\title{
Unified Shear-Flexural Model for Vibration Control of Buildings Using Passive Dynamic Absorbers
}

\author{
Hugo Hernández-Barrios $\mathbb{D}^{1},{ }^{1,2}$ Iván F. Huergo, ${ }^{1}$ Carlos Arce-León $\mathbb{D}^{\mathbb{D}},{ }^{3}$ and Carlos M. Patlán ${ }^{2}$ \\ ${ }^{1}$ School of Engineering, Universidad Nacional Autónoma de México, Mexico City, Mexico \\ ${ }^{2}$ School of Engineering, Universidad Michoacana de San Nicolás de Hidalgo, Morelia, Mexico \\ ${ }^{3}$ Multidisciplinary Research Unit, FES Acatlán-UNAM, Naucalpan, Mexico \\ Correspondence should be addressed to Hugo Hernández-Barrios; hugohernandezbarrios@yahoo.com.mx
}

Received 4 May 2020; Revised 25 June 2020; Accepted 30 June 2020; Published 6 August 2020

Academic Editor: Said Elias

Copyright (c) 2020 Hugo Hernández-Barrios et al. This is an open access article distributed under the Creative Commons Attribution License, which permits unrestricted use, distribution, and reproduction in any medium, provided the original work is properly cited.

\begin{abstract}
A unified design model is proposed for various kinds of passive dynamic absorbers (PDAs) attached to buildings with different lateral resisting systems. A total of five different PDAs are considered in this study: (1) tuned mass damper (TMD), (2) circular tuned sloshing damper (C-TSD), (3) rectangular tuned sloshing damper (R-TSD), (4) two-way liquid damper (TWLD), and (5) pendulum tuned mass damper (PTMD). The unified model consists of a coupled shear-flexural (CSF) discrete model with equivalent tuned mass dampers (TMDs), which allows the consideration of intermediate modes of lateral deformation. By modifying the nondimensional lateral stiffness ratio, the CSF model can consider lateral deformations varying from those of a flexural cantilever beam to those of a shear cantilever beam. The unified model was applied to a 144-meter-tall building located in the Valley of Mexico, which was subjected to both seismic and along-wind loads. The building has similar fundamental periods of vibration and different nondimensional lateral stiffness ratios for both translational directions, which shows the importance of considering both bending and shear stiffness in the design of PDAs. The results show a great effectiveness of PDAs in controlling along-wind RMS accelerations of the building; on the contrary, PDAs were ineffective in controlling peak lateral displacements. For a single PDA attached at the rooftop level, the maximum possible value of the PDA mass efficiency index increases as the nondimensional lateral stiffness ratio decreases; therefore, there is an increase in the vibration control effectiveness of PDAs for lateral flexural-type deformations.
\end{abstract}

\section{Introduction}

Increasing urbanization in recent decades has led to the construction of high-rise buildings, which are usually susceptible to wind loads worldwide. However, tall buildings located in seismic zones, e.g., cities along the Pacific coast of Mexico, are not only subjected to wind loads but also to seismic ones. While shear and flexural beams can provide adequate models for certain types of buildings, there are many types for which these two extreme modes of lateral deformation may not be appropriate. Generally speaking, low-rise buildings usually deform as pure shear beams, whereas in medium-rise and high-rise buildings, the flexural deformation is as significant as the shear deformation.
Complex structural systems as high-rise buildings can be reduced to equivalent continuous beam models using two different arrangements of bending and shear stiffness: (1) a continuous Timoshenko beam model that reflects a series coupling [1] and (2) a coupled shear-flexural (CSF) continuous model that couples both stiffness in parallel [2]. Dym and Williams [3] concluded that a series coupling of both stiffness does not display the correct dependence of frequency on building height, particularly in shear wallframe buildings and tube-and-core constructions with the parallel nature of the two-beam model in which transverse displacements due to bending and to shear are identical. In conclusion, it appears that the CSF model seems to be the best model for estimating the frequencies of medium-rise to 
high-rise buildings because it provides predictions that are consistent with the observed data [3].

Generally speaking, the common techniques used for vibration control can be classified into three categories: active, passive, and hybrid devices. Unlike active vibration control $[4,5]$, passive vibration control $[6,7]$ dissipates energy without incorporating mechanisms powered by an external energy source. On the other hand, hybrid vibration control [4, 8-14] combines features of active and passive control systems. Passive dynamic absorbers (PDAs) are devices tuned to a particular structural frequency so that when that frequency is excited, the device resonates out of phase with the structural motion. There are several types of PDAs such as tuned mass dampers (TMDs), tuned liquid dampers (TLDs), and pendulum tuned mass dampers (PTMDs), among others.

A tuned mass damper (TMD) is a device consisting of a mass, a spring, and a damper that is attached to a structure in order to reduce its dynamic response. Den Hartog [15] derived the formula for the optimum values of the TMD parameters for an undamped single degree of freedom (SDOF) structure subjected to harmonic excitation. Warburton and Ayorinde [16] derived closed-form expressions for obtaining TMD parameters for an undamped SDOF system for base harmonic and white noise random excitation. For seismic applications, Sadek et al. [17] suggested a method for estimating the design parameters of TMDs attached to a damped SDOF structure.

A tuned liquid damper (TLD) is a special type of TMD where the mass is replaced by a liquid (usually water). A TLD utilizes the sloshing of the liquid in the container, but only a fraction of the liquid participates in the sloshing motion tuned to the dominant vibration frequency of the primary structure. Tuned liquid column dampers (TLCDs) are a special type of TLDs that rely on the motion of a column of liquid in a U-tube like container to counteract the acting forces on the structures. In a similar way, tuned sloshing dampers (TSDs) are a special type of TLDs consisting of tanks partially filled with liquid that use the sloshing energy of water to reduce the dynamic response of the structure. There are two types of TSDs based on the geometry of the tank: circular tuned sloshing damper (C-TSD) and rectangular tuned sloshing damper (R-TSD). For bidirectional control of building structures, a two-way liquid damper (TWLD) is another special type of TLD that consists of a combination of a TLCD and a R-TSD to mitigate the dynamic response of the primary structure.

Kareem [18] studied the reduction of wind-induced motion in shear buildings using a TSD. Chang and Gu [19] studied the control effects of R-TSDs installed on a tall building that vibrates due to vortex excitation. For industrial practice, Wu et al. [20] proposed some useful guidelines for designing TLCDs for damped SDOF structures under a white noise type of wind excitation. Tait [21] developed equivalent linear damping ratio expressions for structureTSD systems subjected to both sinusoidal and random excitation. Lee et al. [22] explored the effect of the coupled TLCD-TSD force on the dynamic properties of a TWLD. Subsequently, Min et al. [23] developed a design procedure of TWLDs for attenuation of wind-induced responses of tall buildings, whereas Rozas et al. [24] proposed a new bidirectional tuned liquid column damper for controlling the seismic response of structures.

The natural frequencies of a structure are often difficult to predict accurately. For this reason, it is desirable that the natural frequency of the TMD be tunable on site, which can be easily accomplished by using TLDs or PTMDs. A pendulum tuned mass damper (PTMD) consists of a mass supported with cables, which allows the system to behave like a pendulum. Therefore, the device generates a horizontal force that opposes the floor motion. For high-rise buildings with large mass and low frequencies, a cable-supported pendulum system in which the natural frequency is tunable by changing the pendulum length is highly recommended [25]. For both seismic and wind loads, Gerges and Vickery [26] proposed optimum design parameters for PTMDs by using equivalent TMDs. Shu et al. [27] implemented the performance-based analysis and design methodology to assess the seismic vulnerability of a coal-fired power plant and to optimally design its equivalent pendulum-type tuned mass damper system such that the direct losses are minimized.

Assuming the primary structure as a generalized SDOF system, Chang et al. [28, 29] established unified design formulas for various kinds of PDAs (TMD, TLCD, and TSD) under both seismic and wind loads by using equivalent TMDs. Both studies [28,29] demonstrated that PDAs can be modeled as equivalent TMDs; however, PDAs are usually studied using building models that cannot couple the bending and shear stiffness in parallel [30-35]. Balendra et al. [36] studied the effectiveness of TLCDs in reducing the along-wind response of tall buildings using a CSF continuous model subjected to a reduced external force; that is, they did not incorporate the TLCDs in the equations of motion of the CSF continuous model. Afterwards, Huergo and Hernández [37] proposed a CSF discrete model with TMDs, which adequately incorporates the TMDs in the equations of motion; therefore, the main novelty of this paper is the incorporation of different kinds of PDAs into the CSF discrete model by using equivalent TMDs. For practical design purposes, the consideration of different lateral resisting systems by using the CSF discrete model with TMDs [37] could lead structural engineers to optimize not only the design of TMDs but also the design of other kinds of PDAs such as TLDs.

In this paper, Section 2 shows the design procedure of five different kinds of PDAs (TMD, C-TSD, R-TSD, TWLD, and PTMD) by modeling the devices as equivalent TMDs. In Section 3, the five different kinds of PDAs are incorporated into the CSF discrete model [37] in order to reproduce the vibration control of buildings with different lateral resisting systems. In Section 4, the effect of the lateral resisting system on PDAs is shown for the maximum PDA/SDOF nondimensional mass ratio. Assuming a single PDA attached at the rooftop level, Section 5 shows the numerical assessment of a 144-meter-tall building subjected to both seismic and along-wind loads. 


\section{Design Procedure of Passive Dynamic Absorbers}

The aim of Section 2 is to provide a unified analytical formulation for the CSF model with PDAs. The tuning of passive dynamic absorbers (PDAs) to a particular structural frequency achieves input energy dissipation due to the damper inertia force acting on the structure. For engineering purposes, PDAs can be modeled as equivalent tuned mass dampers (TMDs) [26, 28, 29]. Figure 1 shows the geometry of five different kinds of PDAs (TMD, C-TSD, R-TSD, TWLD, and PTMD), where $m_{\mathrm{PDA}}, k_{P D A}$, and $c_{P D A}$ are defined as the mass, spring stiffness, and damping coefficient of the PDA modeled as an equivalent TMD, respectively.

2.1. Tuned Mass Dampers. The mass of a TMD (see Figure $1(\mathrm{a})$ ) is given by the following equation:

$$
m_{\mathrm{PDA}}=\mu m_{\mathrm{SDOF}},
$$

where $\mu$ is the TMD/SDOF nondimensional mass ratio that may be chosen in the range of $1 / 50$ to $1 / 15$ for a first design approach [38] and $m_{\mathrm{SDOF}}$ is the structural mass of an equivalent single degree of freedom (SDOF) system, which is given by the following equation:

$$
m_{\mathrm{SDOF}}=\frac{\left\{\phi_{i}\right\}^{T}[M]\left\{\phi_{i}\right\}}{\phi_{i}^{2}\left(z_{\mathrm{PDA}}\right)},
$$

where $\left\{\phi_{i}\right\}$ is a vector containing the modal amplitudes of the $i$ th lateral mode of vibration of the building that will be tuned to the frequency of the PDA, $[M]$ is the lumped mass matrix of the building, $z_{\mathrm{PDA}}$ is the height above ground level of the attachment point of the PDA, and $\phi_{i}\left(z_{\mathrm{PDA}}\right)$ is the modal amplitude of the $i$ th lateral mode of vibration of the building at $z_{\mathrm{PDA}}$. The angular frequency, spring, stiffness, and damping coefficient of the TMD are defined, respectively, as follows:

$$
\begin{aligned}
& w_{\mathrm{PDA}}=R_{f} w_{i}, \\
& k_{\mathrm{PDA}}=m_{\mathrm{PDA}}\left(w_{\mathrm{PDA}}\right)^{2}, \\
& c_{\mathrm{PDA}}=2 \xi_{\mathrm{PDA}} m_{\mathrm{PDA}} w_{\mathrm{PDA}},
\end{aligned}
$$

where $w_{i}$ is the angular frequency of the ith lateral mode of vibration of the building that will be tuned to the frequency of the TMD, $R_{f}$ is the TMD/SDOF nondimensional frequency ratio, and $\xi_{\mathrm{PDA}}$ is the optimum damping ratio of the TMD. Table 1 shows some optimum tuning conditions for damped TMDs attached to an undamped primary structure [39].

2.2. Circular Tuned Sloshing Dampers. Tuned sloshing dampers (TSDs) can be broadly classified into two categories: shallow-water and deep-water dampers. This classification is based on the ratio of the water surface elevation in the direction of motion to the water depth [18]. In the shallow-water case, the TSD damping originates primarily from energy dissipation through the action of the internal fluid viscous forces and from wave breaking [18]. Wave motions in shallow-water TSDs are generally complex due to strong nonlinearities such as wave breaking; however, shallow-water TSDs provide high damping of liquid sloshing and an efficient moving mass [40]. On the other hand, deepwater TSDs provide low damping and an inefficient moving mass because a large portion of the liquid below the free surface does not participate in sloshing. However, the presence of baffles or screens may further increase the damping $[18,21]$.

It is important to consider the effect of the nonlinear water sloshing when a TSD is employed in a structure subjected to large amplitude excitations such as earthquakes. The presence of several sloshing modes, each with separate frequencies, reduces the inertial forces tuned to damped structural movement [41]. There has been research concerning the effectiveness of sloshing liquid damping systems for high amplitude excitations galore; however, it is important to realize that such systems act more like chaotic energy dissipators as opposed to indirect inertial damping systems [41-43].

On the other hand, when a TSD is subjected to small amplitude excitations, the nonlinearities in its response are largely absent. The amplitudes of motion resulting from wind loading are sufficiently small, so much so that the fundamental sloshing mode of a TSD is practically the only one that is excited. For this reason, and because of the highly periodic nature of wind excitation, TSDs are well suited to reduce structural motion due to wind [41]. Although researchers have extended the theoretical model to account for breaking wave motion in rectangular tuned sloshing dampers (R-TSDs) [44], it is difficult to develop a model for breaking wave motion in circular tuned sloshing dampers (C-TSDs) [43].

According to Chang and $\mathrm{Qu}$ [28], the mass, spring stiffness, and damping coefficient of a linear C-TSD (see Figure $1(\mathrm{~b})$ ) are given by the following equations:

$$
\begin{aligned}
m_{\mathrm{PDA}} & =\frac{\rho \pi r^{3}}{4.39} \tanh \left(\frac{1.84 h}{r}\right), \\
k_{\mathrm{PDA}} & =0.419 \rho \pi g r^{2} \tanh ^{2}\left(\frac{1.84 h}{r}\right), \\
c_{\mathrm{PDA}} & =2 \xi_{\mathrm{PDA}} m_{\mathrm{PDA}} w_{\mathrm{PDA}},
\end{aligned}
$$

where $\rho$ is the liquid density (usually water), $r$ is the radius of the circular tank, $h$ is the liquid depth, $g$ is the gravitational acceleration, and $\xi_{\mathrm{PDA}}$ is the optimum damping ratio of the C-TSD.

Assuming a linear wave and small amplitudes, the fundamental angular frequency of the sloshing liquid is calculated as follows:

$$
w_{\mathrm{PDA}}=\sqrt{\frac{k_{\mathrm{PDA}}}{m_{\mathrm{PDA}}}}=\sqrt{\frac{1.84 g}{r} \tanh \left(\frac{1.84 h}{r}\right)} .
$$




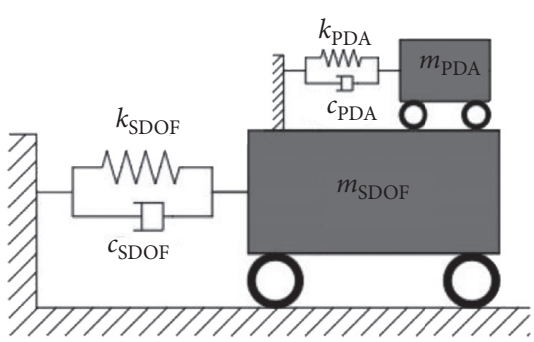

(a)

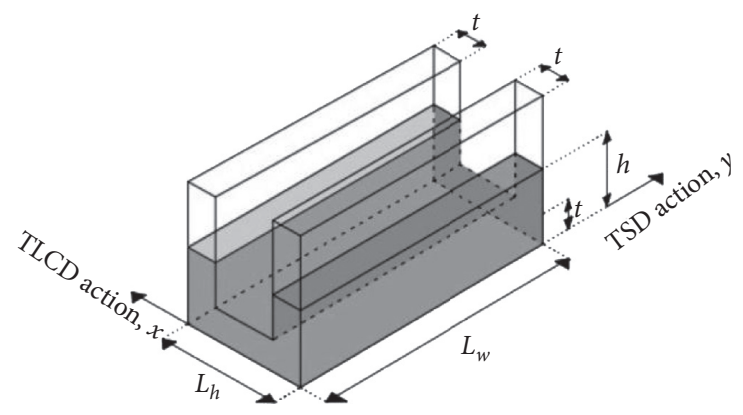

(d)

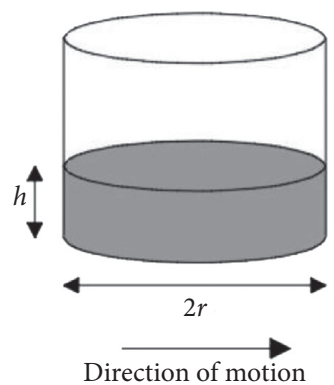

(b)

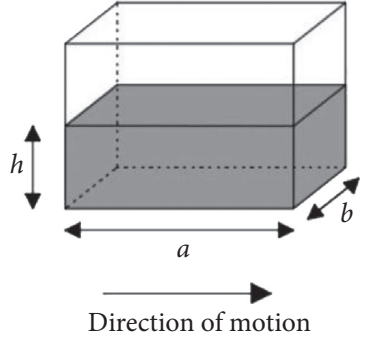

(c)

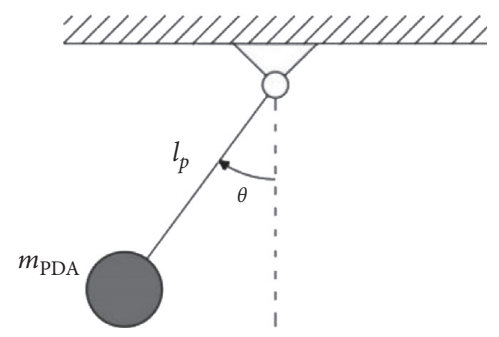

(e)

Figure 1: Geometry of the five PDAs. TMD: tuned mass damper; C-TSD: circular tuned sloshing damper; R-TSD: rectangular tuned sloshing damper; TWLD: two-way liquid damper; PTMD: pendulum tuned mass damper. (a) TMD-structure interaction system. (b) C-TSD. (c) R-TSD. (d) TWLD. (e) PTMD.

TABLE 1: Optimum tuning conditions for damped TMDs attached to an undamped primary structure.

\begin{tabular}{|c|c|c|}
\hline \multirow{2}{*}{ Loading case } & \multirow{2}{*}{ Optimization criteria } & Optimum tuning conditions \\
\hline & & $\xi_{\mathrm{PDA}}$ \\
\hline \multirow{2}{*}{$\begin{array}{l}\text { Harmonic load applied to } \\
\text { primary structure }\end{array}$} & $\begin{array}{l}\text { Minimum relative displacement amplitude of } \\
\text { primary structure }\end{array}$ & $\sqrt{(3 \mu) /\left(8(1+\mu)^{3}\right)}$ \\
\hline & $\begin{array}{l}\text { Minimum relative acceleration amplitude of } \\
\text { primary structure }\end{array}$ & $\sqrt{(3 \mu) / 8(1+0.5 \mu)}$ \\
\hline \multirow[b]{2}{*}{ Harmonic base acceleration } & $\begin{array}{l}\text { Minimum relative displacement amplitude of } \\
\text { primary structure }\end{array}$ & $\sqrt{(3 \mu) /(8(1+\mu)(1-0.5 \mu))}$ \\
\hline & $\begin{array}{c}\text { Minimum absolute acceleration amplitude of } \\
\text { primary structure }\end{array}$ & $\sqrt{(3 \mu) /(8(1+\mu))}$ \\
\hline $\begin{array}{l}\text { Random load applied to } \\
\text { primary structure }\end{array}$ & $\begin{array}{c}\text { Minimum root mean square value of relative } \\
\text { displacement of primary structure }\end{array}$ & $(\sqrt{1-0.5 \mu}) /(1+\mu) \quad \sqrt{(\mu(1+0.75 \mu)) /(4(1+\mu)(1-0.5 \mu))}$ \\
\hline Random base acceleration & $\begin{array}{l}\text { Minimum root mean square value of relative } \\
\text { displacement of primary structure }\end{array}$ & $(\sqrt{1-0.5 \mu}) /(1+\mu) \quad \sqrt{(\mu(1-0.25 \mu)) /(4(1+\mu)(1-0.5 \mu))}$ \\
\hline
\end{tabular}

Substituting equation (3) into equation (7) leads to the following equation:

$$
\begin{aligned}
h & =0.5435 r \tanh ^{-1}\left[\frac{0.5435 r\left(R_{f} w_{i}\right)^{2}}{g}\right] \\
& =0.2718 r \ln \left[\frac{g+0.5435 r\left(R_{f} w_{i}\right)^{2}}{g-0.5435 r\left(R_{f} w_{i}\right)^{2}}\right],
\end{aligned}
$$

where $w_{i}$ is the angular frequency of the ith lateral mode of vibration of the building that will be tuned to the frequency of the PDA and $R_{f}$ is the C-TSD/SDOF nondimensional frequency ratio. In equation (8), only values of $r<g /\left[0.5435\left(R_{f} w_{i}\right)^{2}\right]$ guarantee real values of $h$.

According to Chang $[28,29]$, the C-TSD/SDOF nondimensional mass ratio and the C-TSD mass efficiency index are defined, respectively, as follows:

$$
\begin{aligned}
& \mu=\frac{\rho \pi r^{2} h}{m_{\mathrm{SDOF}}}, \\
& \lambda=\frac{m_{\mathrm{PDA}}}{m_{\mathrm{SDOF}}}=\frac{\rho \pi r^{3}}{4.39 m_{\mathrm{SDOF}}} \tanh \left(\frac{1.84 h}{r}\right),
\end{aligned}
$$

where $m_{\text {SDOF }}$ is the structural mass of an equivalent SDOF system, which was defined in equation (2). Table 2 shows 
TABLe 2: Optimum tuning conditions for TLDs attached to an undamped primary structure.

\begin{tabular}{|c|c|c|c|}
\hline \multirow{2}{*}{ Optimization criteria } & \multirow{2}{*}{ Loading case } & \multicolumn{2}{|r|}{ Optimum tuning conditions } \\
\hline & & $R_{f}$ & $\xi_{\mathrm{PDA}}$ \\
\hline \multirow{3}{*}{$\begin{array}{l}\text { Minimum relative displacement amplitude } \\
\text { of primary structure }\end{array}$} & Seismic load & $(\sqrt{1+\mu-1.5 \lambda}) /(1+\mu)$ & $(1 / 2) \sqrt{(\lambda(1+\mu-1.25 \lambda)) /((1+\mu)(1+\mu-1.5 \lambda))}$ \\
\hline & $\begin{array}{l}\text { Along-wind } \\
\text { load }\end{array}$ & $(\sqrt{1+\mu-0.5 \lambda}) /(1+\mu)$ & $(1 / 2) \sqrt{(\lambda(1+\mu-0.25 \lambda)) /((1+\mu)(1+\mu-0.5 \lambda))}$ \\
\hline & $\begin{array}{l}\text { Across-wind } \\
\text { load }\end{array}$ & $1 /(\sqrt{1+\mu})$ & $\sqrt{(\sqrt{1+\mu}-\sqrt{1+\mu-\lambda}) /(2 \sqrt{1+\mu})}$ \\
\hline
\end{tabular}

some optimum tuning conditions for TLDs attached to an undamped primary structure $[19,29]$.

2.3. Rectangular Tuned Sloshing Dampers. For shallowwater dampers, the movement of the water within a tank is not as neat and easy to predict as the lateral oscillation of a mass-spring system. The presence of several different modes of sloshing coupled with nonlinear effects such as wave breaking and slamming impacts, can make an accurate prediction of sloshing behavior difficult [41]. To account for breaking waves inside rectangular containers, Sun and Fujino [44] proposed two coefficients into the equations of motion: a damping coefficient that represents the increase in liquid damping and the frequency shift coefficient that represents the phase velocity shift of liquid motion. The nonlinear damping force of a rectangular tuned sloshing damper ( $R$ TSD) can be replaced by a linearized generalized damping term by minimizing the error between the actual damping force and the linearized generalized damping force [21, 45].

Neglecting the nonlinear behavior of liquid sloshing, the mass, spring stiffness, and damping coefficient of a R-TSD (see Figure 1(c)) are defined, respectively, as follows [28]:

$$
\begin{aligned}
& m_{\mathrm{PDA}}=\frac{8 \rho b a^{2}}{\pi^{3}} \tanh \left(\frac{\pi h}{a}\right), \\
& k_{\mathrm{PDA}}=\frac{8 \rho b a g}{\pi^{2}} \tanh ^{2}\left(\frac{\pi h}{a}\right), \\
& c_{\mathrm{PDA}}=2 \xi_{\mathrm{PDA}} m_{\mathrm{PDA}} w_{\mathrm{PDA}},
\end{aligned}
$$

where $\rho$ is the liquid density (usually water), $a$ is the length of the TLD along the liquid motion direction, $b$ is the width of the tank, $h$ is the liquid depth, $g$ is the gravitational acceleration, and $\xi_{\mathrm{PDA}}$ is the optimum damping ratio of the R-TSD.

According to the shallow-water wave theory that is applied to the R-TSDs with the depth ratio $h / a$ ranging from 0.04 to 0.5 , the liquid level sloshes within a rectangular container with the following fundamental frequency [40]:

$$
w_{\mathrm{PDA}}=\sqrt{\frac{k_{\mathrm{PDA}}}{m_{\mathrm{PDA}}}}=\sqrt{\frac{\pi g}{a} \tanh \left(\frac{\pi h}{a}\right)} .
$$

Substituting equation (3) into equation (11) leads to the following:

$$
h=\frac{a}{\pi} \tanh ^{-1}\left[\frac{a\left(R_{f} w_{i}\right)^{2}}{\pi g}\right]=\frac{a}{2 \pi} \ln \left[\frac{\pi g+a\left(R_{f} w_{i}\right)^{2}}{\pi g-a\left(R_{f} w_{i}\right)^{2}}\right],
$$

where $w_{i}$ is the angular frequency of the ith lateral mode of vibration of the building that will be tuned to the frequency of the PDA and $R_{f}$ is the R-TSD/SDOF nondimensional frequency ratio. In equation (12), only values of $a<\pi g /\left(R_{f} w_{i}\right)^{2}$ guarantee real values of $h$.

According to Chang $[28,29]$, the R-TSD/SDOF nondimensional mass ratio and the R-TSD mass efficiency index are defined, respectively, as follows:

$$
\begin{aligned}
& \mu=\frac{\rho a b h}{m_{\mathrm{SDOF}}} \\
& \lambda=\frac{m_{\mathrm{PDA}}}{m_{\mathrm{SDOF}}}=\frac{8 \rho b a^{2}}{\pi^{3} m_{\mathrm{SDOF}}} \tanh \left(\frac{\pi h}{a}\right),
\end{aligned}
$$

where $m_{\text {SDOF }}$ is the structural mass of an equivalent SDOF system, which was defined in equation (2). According to Chang et al. $[19,29]$, the values of $\xi_{\mathrm{PDA}}$ and $R_{f}$ can be obtained from Table 2.

2.4. Two-Way Liquid Dampers. Lee et al. [22] proposed a two-way-liquid damper (TWLD) which behaves as both tuned liquid column damper (TLCD) and tuned sloshing damper (TSD) in both orthogonal directions (see Figure 1(d)). For bidirectional control of building structures, the TLCD action ( $x$-direction) is tuned to a particular structural frequency in $x z$ plane and the TSD action $(y$ direction) is tuned to a particular structural frequency in $y z$ plane. To ensure the U-shape, three constrained conditions are required: $2 t<L_{h}, t<h$ and

$$
L_{e}=2 h-t+L_{h}
$$

where $L_{e}$ is the effective length of the TLCD, that is, the total liquid column length; $h$ is the liquid depth; $t$ is the thickness of the TLCD and $L_{h}$ is the horizontal liquid column length.

For both orthogonal directions, the fundamental angular frequencies of both TLCD and TSD are defined, respectively, as follows [23]:

$$
\begin{aligned}
& w_{\mathrm{PDA}, x}=\sqrt{\frac{2 g}{L_{e}}}, \\
& w_{\mathrm{PDA}, y}=\sqrt{\frac{\pi g}{L_{w}} \tanh \left(\frac{\pi h}{L_{w}}\right)},
\end{aligned}
$$

where $g$ is the gravitational acceleration and $L_{w}$ is the width of TSD. 
For TLCD action ( $x$-direction), the TLCD/SDOF nondimensional mass ratio and the TLCD mass efficiency index are defined, respectively, as follows [22, 23]:

$$
\begin{aligned}
& \mu_{x}=\frac{\rho L_{w} t L_{e}}{m_{\mathrm{SDOF}, x}}, \\
& \lambda_{x}=\mu_{x}\left(\frac{L_{h}}{L_{e}}\right)^{2}=\frac{\rho L_{w} t L_{h}^{2}}{L_{e} m_{\mathrm{SDOF}, x}},
\end{aligned}
$$

where $\rho$ is the liquid density (usually water) and $m_{\mathrm{SDOF}, x}$ is the structural mass of an equivalent SDOF system in $x z$ plane. For TSD action ( $y$-direction), the TSD/SDOF nondimensional mass ratio and the TSD mass efficiency index are defined, respectively, as follows $[22,23]$ :

$$
\begin{aligned}
& \mu_{y}=\frac{2 \rho L_{w} t h}{m_{\mathrm{SDOF}, y}} \\
& \lambda_{y}=\beta \mu_{y}=\frac{2 \beta \rho L_{w} t h}{m_{\mathrm{SDOF}, y}},
\end{aligned}
$$

where $m_{\mathrm{SDOF}, y}$ is the structural mass of an equivalent SDOF system in $y z$ plane and $\beta$ is the first modal mass participation factor of liquid sloshing, which is given by the following equation:

$$
\beta=\frac{8 L_{w}}{\pi^{3} h} \tanh \left(\frac{\pi h}{L_{w}}\right) .
$$

According to Figure 1(d), $L_{e}, L_{w}, L_{h}, h$ and $t$ are computed by solving the following system of nonlinear equations:

$$
\begin{aligned}
\rho L_{w} t L_{e}-m_{\mathrm{SDOF}, x} \mu_{x} & =0, \\
2 \rho L_{w} t h-m_{\mathrm{SDOF}, y} \mu_{y} & =0, \\
2 h-t+L_{h}-L_{e} & =0, \\
w_{x z, i} R_{f, x}-\sqrt{\frac{2 g}{L_{e}}} & =0, \\
w_{y z, i} R_{f, y}-\sqrt{\frac{\pi g}{L_{w}} \tanh \left(\frac{\pi h}{L_{w}}\right)} & =0,
\end{aligned}
$$

where $w_{x z, i}$ and $w_{y z, i}$ are the angular frequencies of the $i$ th lateral mode of vibration of the building in $x z$ plane and $y z$ plane, respectively. According to Chang $[19,29], R_{f, x}$ and $R_{f, y}$ can be obtained from Table 2 based on the values of $\mu_{x}$, $\lambda_{x}, \mu_{y}$, and $\lambda_{y}$.

For TLCD action ( $x$-direction), the mass, spring stiffness, and damping coefficient are given by the following equations [22]:

$$
\begin{aligned}
& m_{\mathrm{PDA}, x}=\rho L_{w} t L_{e}, \\
& k_{\mathrm{PDA}, x}=m_{\mathrm{PDA}, x}\left(w_{\mathrm{PDA}, x}\right)^{2}=2 g \rho t L_{w}, \\
& c_{\mathrm{PDA}, x}=2 \xi_{\mathrm{PDA}, x} m_{\mathrm{PDA}, x} w_{\mathrm{PDA}, x},
\end{aligned}
$$

where $\xi_{\mathrm{PDA}, x}$ can be obtained from Table 2 based on the values of $\mu_{x}$ and $\lambda_{x}$. For TSD action ( $y$-direction), the mass, spring stiffness and damping coefficient are given by [22]

$$
\begin{aligned}
m_{\mathrm{PDA}, y} & =\beta m_{\mathrm{PDA}, x}=\frac{8 L_{w}^{2} \rho t L_{e}}{\pi^{3} h} \tanh \left(\frac{\pi h}{L_{w}}\right), \\
k_{\mathrm{PDA}, y} & =m_{\mathrm{PDA}, y}\left(w_{\mathrm{PDA}, y}\right)^{2}=\pi g \beta \rho t L_{e} \tanh \left(\frac{\pi h}{L_{w}}\right) \\
& =\frac{8 L_{w} g p t L_{e}}{\pi^{2} h} \tanh ^{2}\left(\frac{\pi h}{L_{w}}\right), \\
c_{\mathrm{PDA}, y} & =2 \xi_{\mathrm{PDA}, y} m_{\mathrm{PDA}, y} w_{\mathrm{PDA}, y},
\end{aligned}
$$

where $\xi_{\mathrm{PDA}, y}$ can be obtained from Table 2 based on the values of $\mu_{y}$ and $\lambda_{y}$.

2.5. Pendulum Tuned Mass Dampers. Neglecting both the rotational stiffness and rotational damping coefficient of the pendulum, the mass, spring stiffness, and damping coefficient of a PTMD (see Figure 1(e)) are defined, respectively, as follows [46]:

$$
\begin{aligned}
m_{\mathrm{PDA}} & =\mu m_{\mathrm{SDOF}}, \\
k_{\mathrm{PDA}} & =\frac{m_{\mathrm{PDA}} g}{l_{p}}, \\
c_{\mathrm{PDA}} & =2 \xi_{\mathrm{PDA}} m_{\mathrm{PDA}} w_{\mathrm{PDA}},
\end{aligned}
$$

where $\mu$ is the PTMD/SDOF nondimensional mass ratio that may be chosen in the range of $1 / 50$ to $1 / 15$ for a first design approach [38]; $m_{\mathrm{SDOF}}$ is the structural mass of an equivalent SDOF system, which was defined in equation (2); $g$ is the gravitational acceleration; $l_{p}$ is the pendulum length; $\xi_{\mathrm{PDA}}$ is the damping ratio of the PTMD; and $w_{\mathrm{PDA}}$ is the angular frequency of the pendulum, which is given by the following equation:

$$
w_{\mathrm{PDA}}=\sqrt{\frac{k_{\mathrm{PDA}}}{m_{\mathrm{PDA}}}}=\sqrt{\frac{g}{l_{p}}} .
$$

Substituting equation (3) into equation (27) leads to the following equation:

$$
l_{p}=\frac{g}{\left(R_{f} w_{i}\right)^{2}},
$$

where $w_{i}$ is the angular frequency of the $i$ th lateral mode of vibration of the building that will be tuned to the frequency of the PTMD and $R_{f}$ is the PTMD/SDOF nondimensional frequency ratio. Table 3 shows some optimum tuning conditions for PTMDs attached to an undamped primary structure [26].

\section{Coupled Shear-Flexural Discrete Model with PDAs}

Huergo and Hernández [37] proposed a CSF discrete model with TMDs, which adequately reproduces the lateral deformation of buildings with different lateral resisting 
TABLE 3: Optimum tuning conditions for PTMDs attached to an undamped primary structure.

\begin{tabular}{|c|c|c|}
\hline \multirow{2}{*}{ Optimization criteria } & \multirow{2}{*}{ Excitation } & Optimum tuning conditions \\
\hline & & $R_{f} \quad \xi_{\mathrm{PDA}}$ \\
\hline $\begin{array}{l}\text { Minimum root mean square value of relative displacement of } \\
\text { primary structure }\end{array}$ & $\begin{array}{c}\text { Force } \\
\text { Base } \\
\text { acceleration }\end{array}$ & $\begin{array}{ll}(\sqrt{1+0.5 \mu}) /(1+\mu) & \sqrt{\left(\mu+0.75 \mu^{2}\right) /\left(4+6 \mu+2 \mu^{2}\right)} \\
(\sqrt{1-0.5 \mu}) /(1+\mu) & \sqrt{\left(\mu-0.25 \mu^{2}\right) /\left(4+2 \mu-2 \mu^{2}\right)}\end{array}$ \\
\hline
\end{tabular}

systems. In this section, five different kinds of PDAs (TMD, C-TSD, R-TSD, TWLD, and PTMD) are unified by using equivalent TMDs. Therefore, a fixed-base $\mathrm{N}$-story building with $N_{\text {PDA }}$ PDAs can be schematically represented as shown in Figure 2.

According to Figure 2, the shear wall (flexural beam) and rigid frame (shear beam) are assumed to be connected by a finite number of axially rigid members that transmit horizontal forces; thus, both cantilever beams in the coupled system undergo the same lateral deformation, $u(z, t)$. For $j=1,2,3, \ldots, N$, the $j$ th axially rigid member is represented by a spring whose stiffness tends to infinity, that is, $k_{j}^{a} \longrightarrow \infty$, which guarantees a parallel coupling of the bending and shear stiffness of the building. The total length of each cantilever beam, $H$, is discretized into $N$ linear finite elements, where the length of the $j$ th finite element is denoted by $L_{j}(j=1,2,3, \ldots, N)$. The mass, spring stiffness, and damping coefficient of the jth PDA are represented by $m_{P D A, j}, k_{P D A, j}$ and $c_{P D A, j}$, respectively, whereas the lateral displacement in the time domain of the $j$ th PDA is represented as $u_{\mathrm{PDA}, j}(t)$.

If floor masses and lateral stiffness are assumed to remain constant along the height of the building, the degree of participation of overall flexural and overall shear deformations in the CSF model is controlled by a nondimensional lateral stiffness ratio given by the following equation:

$$
\alpha=H \sqrt{\frac{\mathrm{GA}^{S}}{\mathrm{EI}}}
$$

where $E I$ is the flexural rigidity of the building and $G A^{S}$ is the effective shear rigidity of the building. A value of $\alpha \longrightarrow 0$ represents a pure flexural model (Euler-Bernoulli beam), whereas a value of $\alpha \longrightarrow \infty$ represents a pure shear model. According to Miranda and Reyes [47], the lateral deformation of shear wall buildings, shear wall-frame buildings, and moment-resisting frames can usually be approximated by using values of $0 \leq \alpha \leq 2,1.5 \leq \alpha \leq 6$, and $5 \leq \alpha \leq 20$, respectively. According to Miranda and Taghavi [2], EI and $\mathrm{GA}^{S}$ are given by the following equation:

$$
\begin{aligned}
\mathrm{EI} & =\frac{4 \bar{m} \pi^{2} H^{4}}{\left(T_{1} \gamma_{1}\right)^{2}\left(\gamma_{1}^{2}+\alpha^{2}\right)}, \\
\mathrm{GA}^{S} & =\frac{4 \bar{m} \pi^{2} \alpha^{2} H^{2}}{\left(T_{1} \gamma_{1}\right)^{2}\left(\gamma_{1}^{2}+\alpha^{2}\right)},
\end{aligned}
$$

where $\bar{m}$ is the mass per unit length of the building; $H$ is the total height of the building; $T_{1}$ is the fundamental period of vibration of the fixed-base building, which can be computed by any of the existing empirical formulas [48-52]; and $\gamma_{1}$ is an eigenvalue parameter related to the first mode shape of the CSF continuous model, that is, the first root of the following characteristic equation [2]:

$$
\begin{aligned}
2 & +\left(2+\frac{\alpha^{4}}{\gamma_{i}^{2}\left(\alpha^{2}+\gamma_{i}^{2}\right)}\right) \cos \left(\gamma_{i}\right) \cosh \left(\sqrt{\alpha^{2}+\gamma_{i}^{2}}\right) \\
& +\left(\frac{\alpha^{2}}{\gamma_{i} \sqrt{\alpha^{2}+\gamma_{i}^{2}}}\right) \sin \left(\gamma_{i}\right) \sinh \left(\sqrt{\alpha^{2}+\gamma_{i}^{2}}\right)=0,
\end{aligned}
$$

where $i=1,2,3, \ldots, \infty$. In a pure shear model, $\alpha \longrightarrow \infty$ and $\gamma_{1} \longrightarrow \pi / 2$; however, Miranda and Reyes [47] indicated that $\alpha=20$ represents a model very close to the pure shear model. Figure 3 shows the first root of equation (32) and its corresponding polynomial curve fitting.

For $0 \leq \alpha \leq 20$, the polynomial curve fitting shown in Figure 3 is given by the following equation:

$$
\begin{aligned}
\gamma_{1}= & \left(8.0564 \times 10^{-10}\right) \alpha^{7}-\left(1.3677 \times 10^{-7}\right) \alpha^{6} \\
& +\left(8.4444 \times 10^{-6}\right) \alpha^{5}-\left(2.5511 \times 10^{-4}\right) \alpha^{4} \\
& +\left(4.0722 \times 10^{-3}\right) \alpha^{3}-\left(3.2706 \times 10^{-2}\right) \alpha^{2} \\
& +\left(9.0619 \times 10^{-2}\right) \alpha+1.8603 .
\end{aligned}
$$

Neglecting axial deformation, each node of each cantilever beam (see Figure 2(b)) has two local degrees of freedom (transverse displacement and rotation). According to the Euler-Bernoulli beam theory, a $4 \times 4$ stiffness matrix is assumed for each finite element related to the flexural cantilever beam, considering the flexural rigidity, EI, shown in equation (30). On the other hand, according to the Timoshenko beam theory, a $4 \times 4$ stiffness matrix is assumed for each finite element related to the shear cantilever beam, considering an equivalent flexural rigidity, $(\mathrm{EI})^{S} \longrightarrow \infty$, and the effective shear rigidity, $\mathrm{GA}^{S}$, shown in equation (31). For the shear cantilever beam, pure shear deformation is guaranteed, regardless of the slenderness ratio, by assuming that $(\mathrm{EI})^{S} \longrightarrow \infty[37]$. Then, the $2 N \times 2 N$ stiffness matrices of both cantilever beams are assembled by the conventional numerical assembly technique for the finite element method. Subsequently, the condensed stiffness matrix of the decoupled flexural beam, $\left[K_{\Delta}^{F}\right]_{N \times N}$, and the condensed stiffness matrix of the decoupled shear beam, $\left[K_{\Delta}^{S}\right]_{N \times N}$, are computed by the well-known static condensation technique [53], considering that only translational degrees of freedom remain active. Reference [37] contains more explicit details on the formulation of the condensed stiffness matrices of both decoupled beams. 


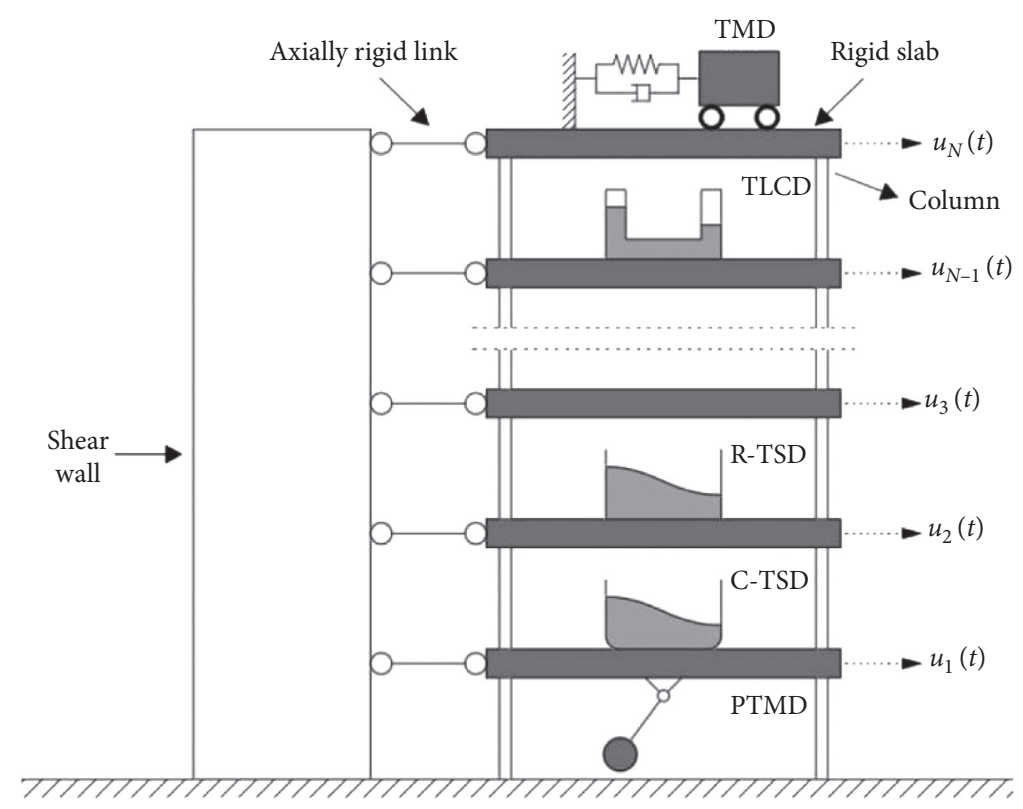

(a)

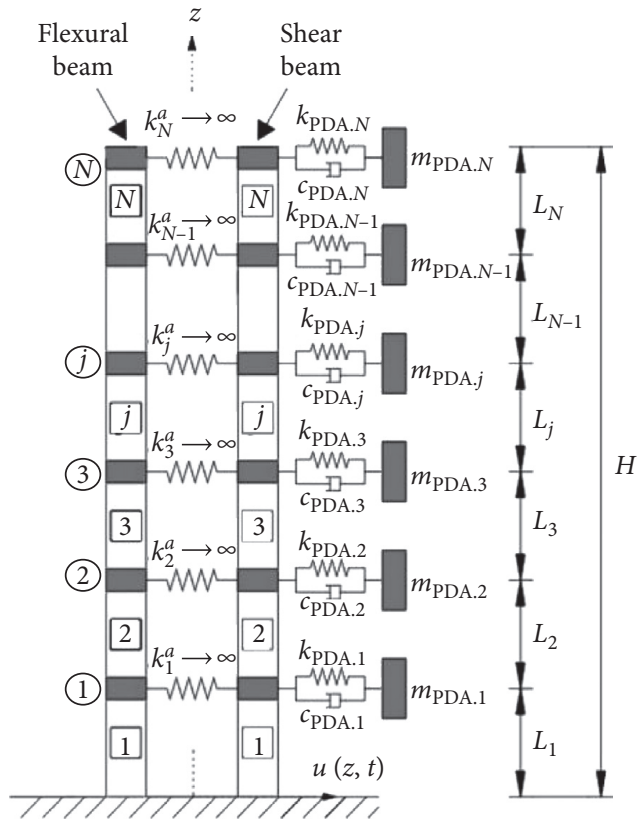

(b)

FIGURE 2: Coupled shear-flexural model for an $N$-story building with PDAs. (a) Sketch. (b) Equivalent discrete model [37].

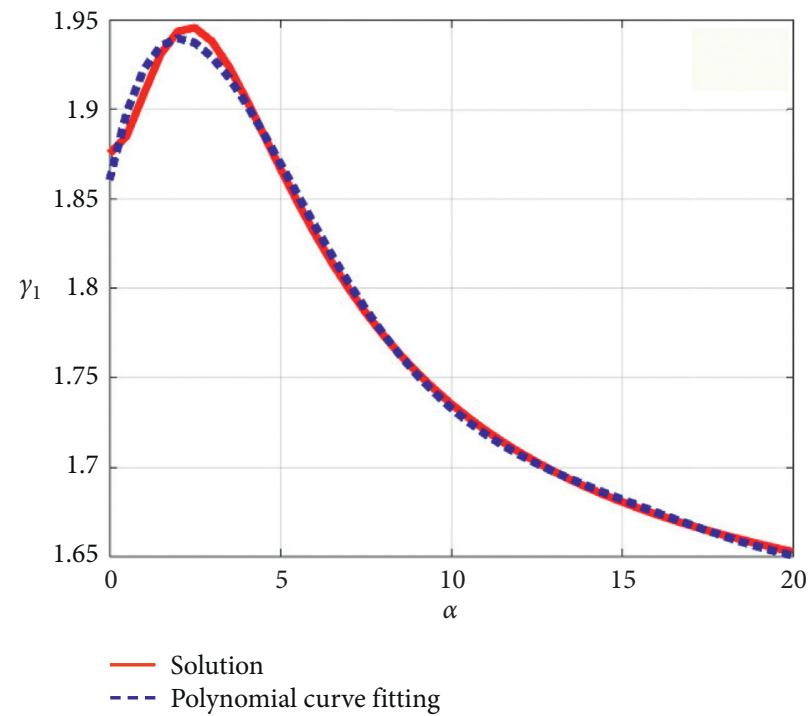

FIGURE 3: First root of the characteristic equation of the fixed-base CSF continuous model.

The lumped mass at the $j$ th story of the building is represented by $m_{j}(j=1,2,3, \ldots, N)$ in such a way that $m_{N}=$ $0.5 \bar{m}\left(L_{N}\right)$ and $m_{n}=0.5 \bar{m}\left(L_{n}+L_{n+1}\right)$, where $n=1,2,3$, $\ldots,(N-1)$ and $\bar{m}$ is the mass per unit length of the building. Then, the total mass of the building is split in half; thereby, the lumped mass matrices of both decoupled beams are represented as $\left[M_{\Delta}^{F}\right]_{N \times N}=\left[M_{\Delta}^{S}\right]_{N \times N}=0.5$ diag $\left[m_{1} \ldots m_{N}\right]$. According to Huergo and Hernández [37], the lateral damping matrix of the decoupled flexural beam, $\left[C_{\Delta}^{F}\right]_{N \times N}$, and the lateral damping matrix of the decoupled shear beam, $\left[C_{\Delta}^{S}\right]_{N \times N}$ are computed with the help of the
Rayleigh's approach [53] using the same damping ratio in all modes.

Assuming that $N_{\text {PDA }}=N$ (see Figure 2(b)), the equations of motion of the CSF model with PDAs can be grouped in the matrix system given by Huergo and Hernández [37]:

$$
\begin{aligned}
& {\left[M_{\mathrm{CSF}}\right]\left\{\ddot{u}_{\mathrm{CSF}}(t)\right\}+\left[C_{\mathrm{CSF}}\right]\left\{\dot{u}_{\mathrm{CSF}}(t)\right\}+\left[K_{\mathrm{CSF}}\right]\left\{u_{\mathrm{CSF}}(t)\right\}} \\
& \quad=\left\{F_{\mathrm{CSF}}(t)\right\},
\end{aligned}
$$

where 


$$
\begin{aligned}
& {\left[M_{\mathrm{CSF}}\right]=\left[\begin{array}{llll}
{\left[M_{\Delta}^{F}\right]} & & & \\
& {\left[M_{\mathrm{PDA}}^{F}\right]} & & \\
& & {\left[M_{\Delta}^{S}\right]} & \\
& & & {\left[M_{\mathrm{PDA}}^{S}\right]}
\end{array}\right] \text {, }} \\
& {\left[M_{\mathrm{PDA}}^{F}\right]=\left[M_{\mathrm{PDA}}^{S}\right]=\frac{1}{2}\left[\begin{array}{lll}
m_{\mathrm{PDA}, 1} & & \\
& \ddots & \\
& & m_{\mathrm{PDA}, N}
\end{array}\right] \text {, }} \\
& {\left[K_{\mathrm{CSF}}\right]=\left[\begin{array}{cccc}
{\left[K_{\Delta}^{F}\right]+\left[K^{A}\right]+\left[K_{\mathrm{PDA}}^{F}\right]} & -\left[K_{\mathrm{PDA}}^{F}\right] & -\left[K^{A}\right] & {[0]_{N \times N}} \\
-\left[K_{\mathrm{PDA}}^{F}\right] & {\left[K_{\mathrm{PDA}}^{F}\right]} & {[0]_{N \times N}} & {[0]_{N \times N}} \\
-\left[K^{A}\right] & {[0]_{N \times N}} & {\left[K_{\Delta}^{S}\right]+\left[K^{A}\right]+\left[K_{\mathrm{PDA}}^{S}\right]} & -\left[K_{\mathrm{PDA}}^{S}\right] \\
{[0]_{N \times N}} & {[0]_{N \times N}} & -\left[K_{\mathrm{PDA}}^{S}\right] & {\left[K_{\mathrm{PDA}}^{S}\right]}
\end{array}\right],} \\
& {\left[K^{A}\right]=\left[\begin{array}{llll}
k_{1}^{a} \longrightarrow \infty & & \\
& & \ddots & \\
& & k_{N}^{a} \longrightarrow \infty
\end{array}\right],} \\
& {\left[K_{\mathrm{PDA}}^{F}\right]=\left[K_{\mathrm{PDA}}^{S}\right]=\frac{1}{2}\left[\begin{array}{lll}
k_{\mathrm{PDA}, 1} & & \\
& \ddots & \\
& & k_{\mathrm{PDA}, N}
\end{array}\right] \text {, }} \\
& {\left[C_{\mathrm{CSF}}\right]=\left[\begin{array}{cccc}
{\left[C_{\Delta}^{F}\right]+\left[C_{\mathrm{PDA}}^{F}\right]} & -\left[C_{\mathrm{PDA}}^{F}\right] & {[0]_{N \times N}} & {[0]_{N \times N}} \\
-\left[C_{\mathrm{PDA}}^{F}\right] & {\left[C_{\mathrm{PDA}}^{F}\right]} & {[0]_{N \times N}} & {[0]_{N \times N}} \\
{[0]_{N \times N}} & {[0]_{N \times N}} & {\left[C_{\Delta}^{S}\right]+\left[C_{\mathrm{PDA}}^{S}\right]} & -\left[C_{\mathrm{PDA}}^{S}\right] \\
{[0]_{N \times N}} & {[0]_{N \times N}} & -\left[C_{\mathrm{PDA}}^{S}\right] & {\left[C_{\mathrm{PDA}}^{S}\right]}
\end{array}\right],} \\
& {\left[C_{\mathrm{PDA}}^{F}\right]=\left[C_{\mathrm{PDA}}^{S}\right]=\frac{1}{2}\left[\begin{array}{lll}
{ }^{C_{\mathrm{PDA}, 1}} & & \\
& \ddots & \\
& & c_{\mathrm{PDA}, N}
\end{array}\right] \text {, }} \\
& \left\{u_{\mathrm{CSF}}(t)\right\}=\left\{\left\{u_{\Psi}^{F}(t)\right\} \quad\left\{u_{\Psi}^{S}(t)\right\}\right\}^{T}, \\
& \left\{u_{\Psi}^{F}(t)\right\}=\left\{u_{\Psi}^{S}(t)\right\}=\left\{u_{1}(t) \ldots u_{N}(t) u_{\mathrm{PDA}, 1}(t) \ldots u_{\mathrm{PDA}, N}(t)\right\} .
\end{aligned}
$$

For seismic loads, the external forces of the CSF model are given by

$$
\left\{F_{\mathrm{CSF}}(t)\right\}=-\left[M_{\mathrm{CSF}}\right]\{1\}_{4 N \times 1} \ddot{u}_{g}(t),
$$

where $\ddot{u}_{g}(t)$ is the horizontal ground acceleration, whereas for wind loads, the external forces of the coupled system are given by the following equation:

$$
\left\{F_{\mathrm{CSF}}(t)\right\}=\frac{1}{2}\left\{F_{1}(t) \ldots F_{N}(t)\{0\}_{1 X N} F_{1}(t) \ldots F_{N}(t)\{0\}_{1 X N}\right\}^{T},
$$

where $F_{j}(t)$ is the wind force acting on the $j$ th story.

The matrix equation (34) can be expressed as follows:

$$
\{\dot{q}(t)\}=[A]\{q(t)\}+\left[F_{e}(t)\right],
$$

where for $N_{\mathrm{PDA}}=N$,

$$
\begin{aligned}
& \{q(t)\}=\left\{\begin{array}{l}
\left\{u_{\mathrm{CSF}}(t)\right\} \\
\left\{\dot{u}_{\mathrm{CSF}}(t)\right\}
\end{array}\right\}_{8 N \times 1}, \\
& \{\dot{q}(t)\}=\left\{\begin{array}{l}
\left\{\dot{u}_{\mathrm{CSF}}(t)\right\} \\
\left\{\ddot{u}_{\mathrm{CSF}}(t)\right\}
\end{array}\right\}_{8 N \times 1}, \\
& {[A]=\left[\begin{array}{cc}
{[0]_{4 N \times 4 N}} & {[I]_{4 N \times 4 N}} \\
-\left[M_{\mathrm{CSF}}\right]^{-1}\left[K_{\mathrm{CSF}}\right] & -\left[M_{\mathrm{CSF}}\right]^{-1}\left[C_{\mathrm{CSF}}\right]
\end{array}\right]_{8 N \times 8 N},} \\
& \left\{F_{e}(t)\right\}=\left\{\begin{array}{c}
\{0\}_{4 N \times 1} \\
{\left[M_{\mathrm{CSF}}\right]^{-1}\left\{F_{\mathrm{CSF}}(t)\right\}}
\end{array}\right\}_{8 N \times 1},
\end{aligned}
$$


and $[I]_{4 N \times 4 N}$ is the identity matrix. The matrix equation for a numerical integration solution using the state space method [54] is as follows:

$$
\left\{q\left(t_{v+1}\right)\right\}=e^{[A] \Delta t}\left\{q\left(t_{v}\right)\right\}+e^{[A] \Delta t} \Delta t\left\{F_{e}\left(t_{v}\right)\right\},
$$

where $\Delta t$ is the integration time step.

Once the relative displacements have been determined by equation (48), the element forces for structural design can be determined by static analysis of the structure at each time step. At any instant of time, the equivalent static forces are the external forces that will produce the relative displacements at the same instant of time in the stiffness component of the structure [53].

The ith effective modal mass of the fixed-base CSF model with PDAs is given by the following equation:

$$
m_{\mathrm{eff}, i}=\frac{\left(\left\{\phi_{\mathrm{CSF}, i}\right\}^{T}\left[M_{\mathrm{CSF}}\right]\{1\}_{4 N \times 1}\right)^{2}}{\left\{\phi_{\mathrm{CSF}, i}\right\}^{T}\left[M_{\mathrm{CSF}}\right]\left\{\phi_{\mathrm{CSF}, i}\right\}},
$$

where $\left\{\phi_{\mathrm{CSF}, i}\right\}$ is the $i$ th mode shape vector of the coupled model. Therefore, the participating mass ratio of the $i$ th mode of vibration is defined as $m_{\text {eff } i} / m_{T}$, where the total mass is given by $m_{T}=\sum_{j=1}^{N} m_{j}+m_{\mathrm{PDA}, j}$.

The consideration of $N_{\mathrm{PDA}}<N$ is achieved by assuming that some PDAs have mass, spring stiffness, and damping coefficient equal to zero. In this case, the matrices $\left[M_{\mathrm{CSF}}\right]$, $\left[K_{\mathrm{CSF}}\right]$, and $\left[C_{\mathrm{CSF}}\right]$ will have some rows and columns with all zero entries, which must be removed before performing a linear time-history analysis. In addition, the size of $\left\{u_{\mathrm{CSF}}(t)\right\}$ and $\left\{F_{\mathrm{CSF}}(t)\right\}$ must also be changed.

\section{Effect of the Lateral Resisting System on PDAs}

According to the uniform CSF continuous model [2], equation (2) can be expressed as follows:

$$
m_{\mathrm{SDOF}}=\frac{\bar{m} H \int_{0}^{1} \phi_{i}^{2}(\bar{z}) \mathrm{d} \bar{z}}{\phi_{i}^{2}\left(\bar{z}_{\mathrm{PDA}}\right)},
$$

where $\bar{m}$ is the mass per unit length of the building; $H$ is the total height of the building; $\bar{z}=z / H ; \bar{z}_{\mathrm{PDA}}=z_{\mathrm{PDA}} / H$; and $\phi_{i}(\bar{z})$ is the $i$ th mode shape of the CSF continuous model [2], which is given by the following equation:

$$
\begin{aligned}
\phi_{i}(\bar{z})= & \sin \left(\gamma_{i} \bar{z}\right)-\frac{\gamma_{i}}{\sqrt{\alpha^{2}+\gamma_{i}^{2}}} \sinh \left(\bar{z} \sqrt{\alpha^{2}+\gamma_{i}^{2}}\right) \\
& -\eta_{i} \cos \left(\gamma_{i} \bar{z}\right)+\eta_{i} \cosh \left(\bar{z} \sqrt{\alpha^{2}+\gamma_{i}^{2}}\right),
\end{aligned}
$$

where $i=1,2,3, \ldots, \infty ; \gamma_{i}$ is the $i$ th root of equation (32) and

$$
\eta_{i}=\frac{\gamma_{i}^{2} \sin \left(\gamma_{i}\right)+\gamma_{i} \sqrt{\alpha^{2}+\gamma_{i}^{2}} \sinh \left(\sqrt{\alpha^{2}+\gamma_{i}^{2}}\right)}{\gamma_{i}^{2} \cos \left(\gamma_{i}\right)+\left(\alpha^{2}+\gamma_{i}^{2}\right) \cosh \left(\sqrt{\alpha^{2}+\gamma_{i}^{2}}\right)} .
$$

The effect of the lateral resisting system of the building on the value of $m_{\mathrm{SDOF}}$ is shown in Figure 4, considering different attachment point locations of the PDAs.
For a PDA tuned to the first mode of vibration, Figure 4 shows that for lower stories $m_{\mathrm{SDOF}}$ increases as $\alpha$ decreases; on the contrary, for upper stories, $m_{\mathrm{SDOF}}$ increases as $\alpha$ increases. Therefore, for lower stories, the PDA/SDOF nondimensional mass ratio, $\mu$, increases as $\alpha$ increases; on the contrary, for upper stories, $\mu$ increases as $\alpha$ decreases. In conclusion, a PDA tuned to the first mode of vibration is more effective in controlling vibrations at lower stories when the primary structure deforms like a pure shear beam. On the contrary, its effectiveness in vibration control increases at upper stories for flexural-type deformations.

For both second and third modes of vibration, $m_{\text {SDOF }}$ changes significantly for middle stories as $\alpha$ changes. For the second mode of vibration, $\mu$ increases as $\alpha$ increases when a single PDA is attached in the range $0.2 H \leq z_{\mathrm{PDA}} \leq 0.8 \mathrm{H}$, whereas for the third mode of vibration, $\mu$ increases as $\alpha$ decreases when a single PDA is attached in the range $0.4 H \leq z_{\mathrm{PDA}} \leq H$. Furthermore, for the first three modes of vibration, $\mu$ increases as $\alpha$ decreases when $z_{\mathrm{PDA}}=H$; thus, a single PDA installed at the rooftop level could be more effective for multimode control than an equal-mass PDA installed at lower stories.

According to the shallow water wave theory [40], the depth ratios $h / 2 r$ and $h / a$ of C-TSDs and R-TSDs, respectively, must be ranged from 0.04 to 0.05 . Both depth ratios are generally in this range in order to obtain high damping of liquid sloshing and efficient moving mass [40]; that is, for the same value of $\mu$, the values of $\xi_{\mathrm{PDA}}$ and $m_{\mathrm{PDA}}$ increase as the depth ratio decreases. Assuming shallow water waves with a mass density of $1000 \mathrm{~kg} / \mathrm{m}^{3}$, Figure 5 shows the maximum efficient moving mass computed for both a circular tuned sloshing damper (C-TSD) and a rectangular tuned sloshing damper (R-TSD, $a=b$ ), considering a single TSD on the rooftop level tuned to the fundamental mode of vibration with a depth ratio equal to 0.46 . The geometry and equivalent TMD mass related to Figure 5 are shown in Table 4.

Figure 5 shows that the maximum possible value of the mass efficiency index, $\gamma$, increases as the fundamental period of vibration of the building increases. Figure 5 also shows that $\gamma$ increases as $\alpha$ decreases; thereby, larger TSDs can be installed at the rooftop level in buildings that deform as pure flexural beams in order to increase the effectiveness in vibration control. For the same depth ratios (see Figure 5 and Table 4), $\gamma$ and $m_{\mathrm{PDA}}$ are greater for a square tuned sloshing damper even though the total liquid mass $\mu m_{\mathrm{SDOF}}$, is greater for a circular tuned sloshing damper. Therefore, a R-TSD could be a better option for vibration control than a C-TSD. Furthermore, a R-TSD is a more versatile device because it is able to be tuned to both translational directions by changing the dimensions of the tank.

For the special case of TWLDs, a parametric analysis for different values of $\alpha$ is impractical due to the system of nonlinear equations (19a)-(19e) and the three constrained conditions that ensure the U-shape on the device. However, greater values of $\mu$ and $m_{\mathrm{PDA}}$ can be expected for high-rise buildings that deform as pure flexural beams (see Table 5). In addition, equations (20) and (23) demonstrate that the equivalent TMD mass is always greater for the TLCD action. 


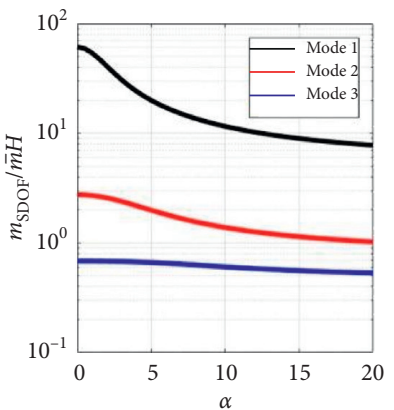

(a)

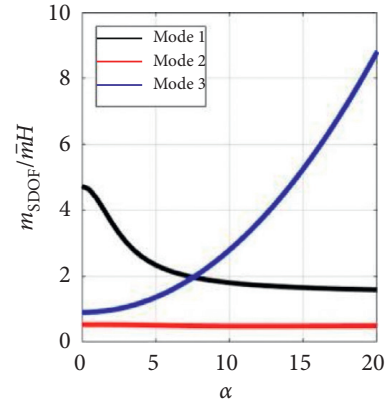

(b)

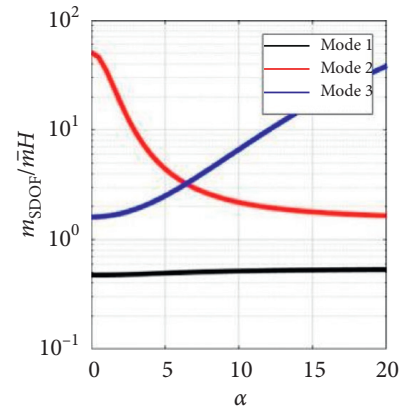

(c)

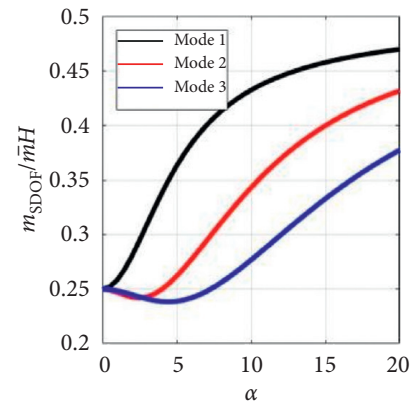

(d)

FIGURE 4: Structural mass of an equivalent SDOF system. (a) $Z_{\mathrm{PDA}}=0.2 H$. (b) $Z_{\mathrm{PDA}}=0.4 H$. (c) $Z_{\mathrm{PDA}}=0.8 H$. (d) $Z_{\mathrm{PDA}}=H$.

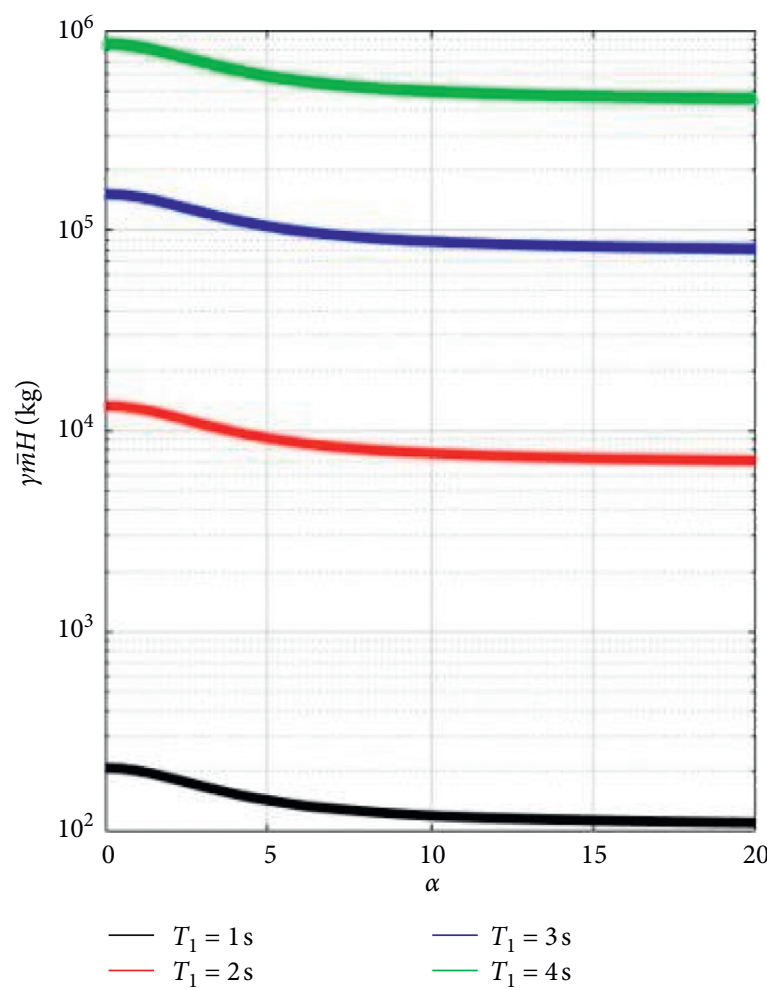

(a)

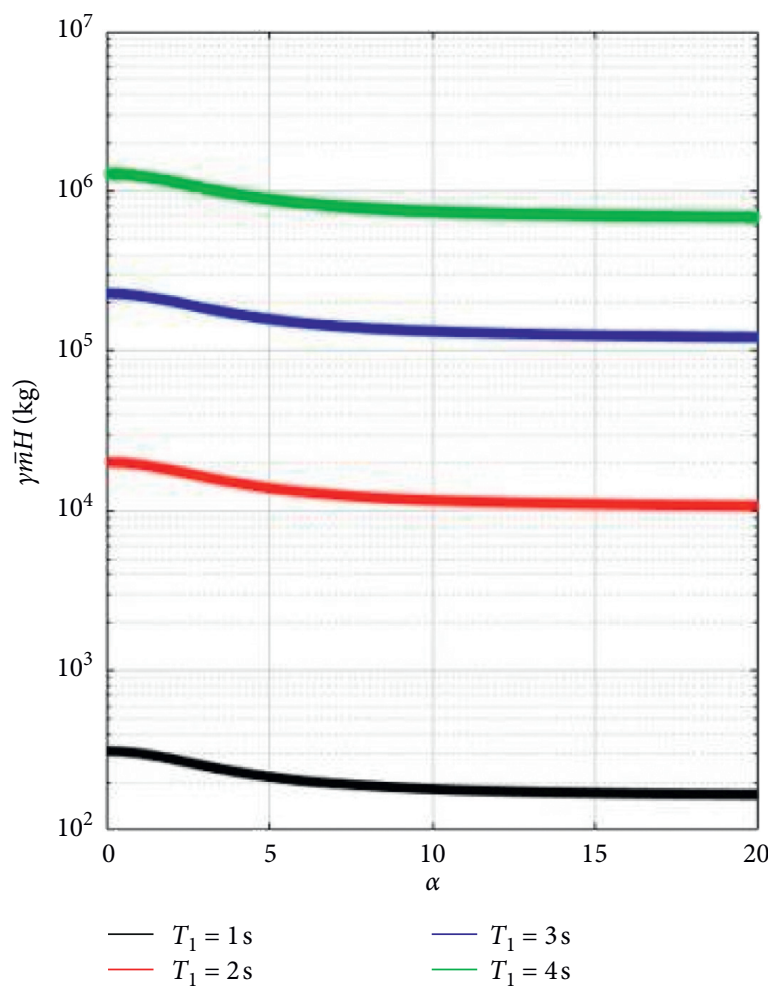

(b)

FIgURe 5: Maximum efficient moving mass of a single TSD attached at $z_{\mathrm{PDA}}=H: h / 2 r=h / a=0.46$ and $R_{f}=1$. (a) C-TSD. (b) R-TSD $(a=b)$.

TABLE 4: Geometry and equivalent TMD mass of a single TSD attached at $z_{\mathrm{PDA}}=H: h / 2 r=h / a=0.46$ and $R_{f}=1$.

\begin{tabular}{|c|c|c|c|c|c|c|}
\hline$T_{1}(s)$ & Type of TSD & $2 r(\mathrm{~cm})$ & $a=b(\mathrm{~cm})$ & $h(\mathrm{~cm})$ & $\mu m_{\text {SDOF }}(\mathrm{kg})$ & $m_{\mathrm{PDA}}(\mathrm{kg})$ \\
\hline \multirow{2}{*}{1} & C-TSD & 85.44 & - & 39.28 & 225.23 & 52.13 \\
\hline & R-TSD & - & 69.82 & 32.07 & 156.32 & 78.52 \\
\hline \multirow{2}{*}{2} & C-TSD & 341.76 & - & 157.13 & 14414 & 3336.6 \\
\hline & R-TSD & - & 279.26 & 128.28 & 10004 & 5025.4 \\
\hline \multirow{2}{*}{3} & C-TSD & 768.97 & - & 353.54 & 164190 & 38006 \\
\hline & R-TSD & - & 628.59 & 289.1 & 114230 & 57333 \\
\hline \multirow{2}{*}{4} & C-TSD & 1367.1 & - & 628.52 & 922530 & 213540 \\
\hline & R-TSD & - & 1117 & 513.12 & 640270 & 321620 \\
\hline
\end{tabular}


TABLE 5: Numerical example of the maximum mass parameters of a TWLD: $T_{1, x}=T_{1, y}=H / 46, \bar{m}=200000 \mathrm{~kg} / \mathrm{m}$, and $R_{f}=1$.

\begin{tabular}{|c|c|c|c|c|c|c|c|c|}
\hline \multirow{2}{*}{$T_{1, x}(\mathrm{~s})$} & \multirow{2}{*}{$T_{1, y}(\mathrm{~s})$} & \multirow{2}{*}{$\alpha$} & \multicolumn{2}{|c|}{$\mu$} & \multicolumn{2}{|c|}{$\gamma$} & \multicolumn{2}{|c|}{$m_{\mathrm{PDA}}(\mathrm{kg})$} \\
\hline & & & TLCD action & TSD action & TLCD action & TSD action & TLCD action & TSD action \\
\hline \multirow{2}{*}{4} & \multirow{2}{*}{4} & 0 & 0.015 & 0.01 & 0.0049 & 0.0064 & 138000 & 88297 \\
\hline & & $\infty$ & - & - & - & - & - & - \\
\hline \multirow{2}{*}{6} & \multirow{2}{*}{6} & 0 & 0.04 & 0.035 & 0.0016 & 0.021 & 552000 & 326310 \\
\hline & & $\infty$ & 0.015 & 0.01 & 0.0022 & 0.0064 & 414000 & 265410 \\
\hline \multirow{2}{*}{8} & \multirow{2}{*}{8} & 0 & 0.035 & 0.03 & 0.022 & 0.020 & 644000 & 431030 \\
\hline & & $\infty$ & 0.015 & 0.01 & 0.0018 & 0.0064 & 552000 & 353190 \\
\hline
\end{tabular}

For the rooftop level, the same behavior occurs for the solid mass vibration absorbers (TMD and PTMD). That is, the maximum possible value of $\mu$ increases as $T_{1}$ increases and $\alpha$ decreases; however, the mass efficiency index, $\gamma$, for both devices is equal to one. Therefore, solid mass vibration absorbers generally are more effective in vibration control, even though both devices are more expensive than tuned liquid dampers. For PTMDs, the pendulum length increases as the fundamental period of vibration of the building increases.

According to Section 2, the PDA/SDOF nondimensional frequency ratio, $R_{f}$, and the PDA optimum damping ratio, $\xi_{\text {PDA }}$, represent the most important parameters for optimizing the vibration control of buildings. However, scientific literature $[17,19,26,29,39]$ only features formulas for $R_{f}$ and $\xi_{\mathrm{PDA}}$ that do not include the nondimensional lateral stiffness ratio, $\alpha$. In future works, the optimum tuning conditions will be studied by using the CSF model with TMDs [37] subjected to several loading cases.

\section{Numerical Example}

In this section, the improved CSF model (see Figure 2(a)) is used to assess the vibration control of a 37-story building located in the Valley of Mexico (see Figure 6(a)). The length, depth, and height of the building are $44 \mathrm{~m}, 22 \mathrm{~m}$, and $144.24 \mathrm{~m}$, respectively. The building has composite steel deck floors with $4 \mathrm{~cm}$ concrete slabs (see Figure 6(b)). The lateral resisting system of the building in $x$-direction consists of moment-resisting frames. On the other hand, the lateral resisting system of the building in $y$-direction consists of a combination of $12 \mathrm{~cm}$ masonry shear walls and braced frames. The mechanical properties and dimensions of the structural elements of the building are described in detail by Huergo et al. [55]. For both translational directions, the first lateral modes of vibration of a fixed-base 3D finite element model (FEM) are shown in Figure 7.

The building was idealized as a fixed-base CSF discrete model, where each beam was discretized into 37 finite elements of equal length, that is, $L_{j}=3.8984 \mathrm{~m}$ for $j=1,2,3, \ldots, 37$. For this numerical example, it was assumed that $(\mathrm{EI})^{S}=1 \times 10^{100} \mathrm{Nm}^{2}$, which guarantees a pure shear deformation for the shear cantilever beam. According to equation (38), it was assumed that $k_{j}^{a}=1 \times 10^{15} \mathrm{~N} / \mathrm{m}$ for $j=1,2,3, \ldots, 37$, which guarantees the parallel coupling between the flexural and shear cantilever beams. Table 6 shows the mechanical properties of the equivalent fixed-base CSF model. For the first mode shape in both translational directions, Figure 8 shows a comparison between the fixedbase 3D FEM and the fixed-base CSF continuous model [2]. Furthermore, Table 7 and Figure 9 show the first three modes of vibration of the fixed-base building in both translational directions, which proves that the assumed values of $\alpha$ adequately represent the higher modes of vibration.

A single PDA (TMD, C-TSD, R-TSD, TWLD, and PTMD) attached at $z_{\mathrm{PDA}}=H$ was tuned to $T_{x z, 1}=3.65 \mathrm{~s}$ and $T_{y z, 1}=3.44 \mathrm{~s}$. Assuming the Cartesian coordinate system shown in Figure 6(b), the structural masses of the equivalent $\mathrm{SDOF}$ systems at $z_{\mathrm{PDA}}=H$ are $m_{\mathrm{SDOF}, x}=$ $1.6996 \times 10^{7} \mathrm{kgand} m_{\mathrm{SDOF}, y}=1.1009 \times 10^{7} \mathrm{~kg}$ for $x z$ plane and $y z$ plane, respectively. All the PDAs were optimized based on Tables 1-3. For the special case of a single TLD (CTSD, R-TSD, and TWLD), the device was designed in such a way that its natural frequency is tunable by changing the liquid depth, assuming that the mass density of the water inside the container is equal to $1000 \mathrm{~kg} / \mathrm{m}^{3}$.

According to the shallow-water wave theory [40], the maximum possible values of $\mu$ for C-TSDs were computed in such a way that both a real solution and a depth ratio of $h / 2 r<0.5$ are guaranteed. The same values of $\mu$ were assumed for R-TSDs, which also guarantees shallow-water waves for rectangular containers. For R-TSDs, the depth ratio, $h / a$, is generally in the range of 0.04 to 0.5 in order to obtain high damping of liquid sloshing and efficient moving mass; that is, for the same value of $\mu$, the values of $\xi_{\mathrm{PDA}}$ and $m_{\mathrm{PDA}}$ increase as the ratio $h / a$ decreases. For both TMD and PTMD cases, the same values of $\mu$ computed for C-TSDs and R-TSDs were chosen in order to compare the effectiveness of the four different PDAs (TMD, PTMD, C-TSD, and R-TSD) in controlling the dynamic response of the building in both translational directions. For the TWLD case, the TLCD action ( $x$-direction) and the TSD action ( $y$-direction) take place in $x z$ plane and $y z$ plane, respectively; however, the maximum possible values of $\mu$ are lower compared to those computed for the other four PDAs (TMD, PTMD, C-TSD, and R-TSD). The geometry and dynamic properties of the five different PDAs are shown in Tables 8-12.

For the numerical example, geometry and dynamic properties of the PDAs are shown in Tables 8-12, where $T_{\text {PDA }}$ is the fundamental period of vibration of the PDA.

5.1. Earthquake-Induced Vibrations. For buildings without passive energy dissipation devices, the elastic CSF model is not useful when strong earthquakes generate an inelastic 


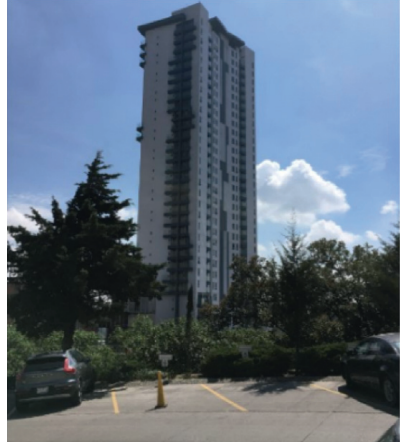

(a)

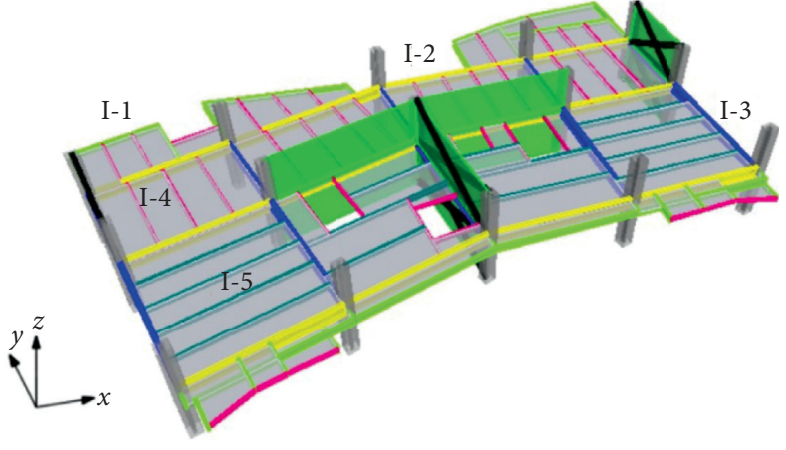

(b)

FIgURE 6: 144-meter-tall building located in the Valley of Mexico [55]. (a) General view. (b) Floor system.

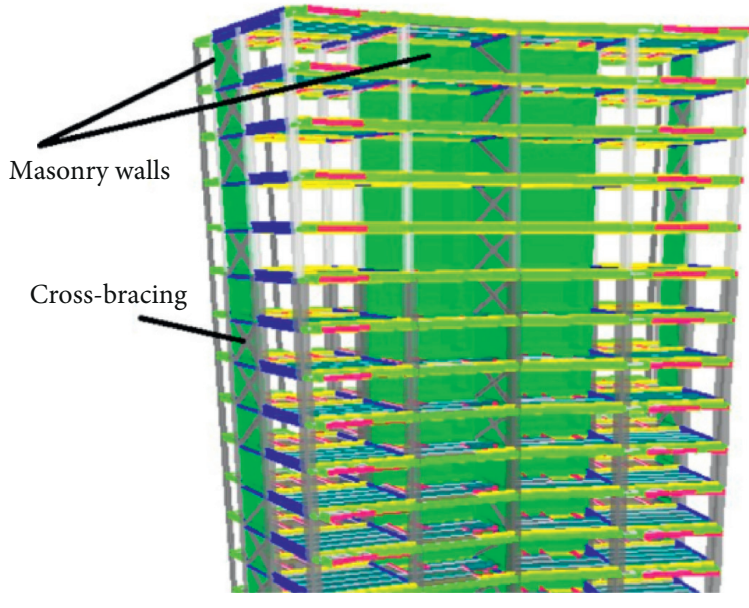

(a)

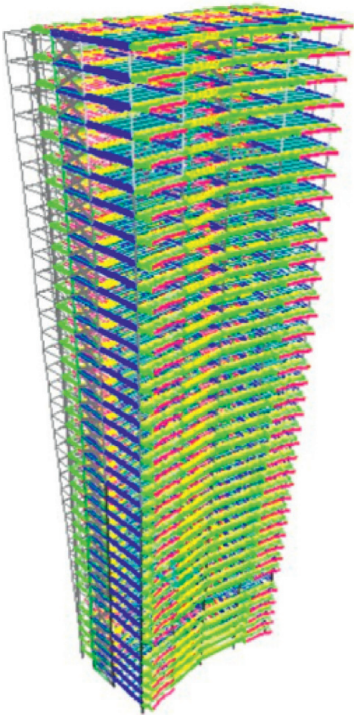

(b)

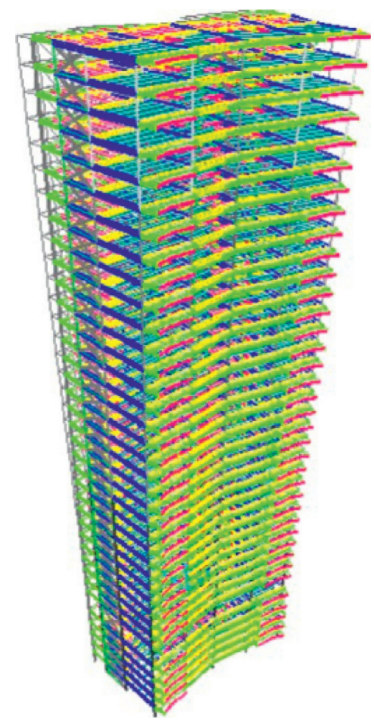

(c)

Figure 7: First lateral modes of vibration of a fixed-base 3D FEM [55]. (a) Lateral resisting system. (b) $T_{x z, 1}=3.65 \mathrm{~s}$. (c) $T_{y z, 1}=3.44 \mathrm{~s}$.

TABle 6: Mechanical properties of the fixed-base CSF discrete model.

\begin{tabular}{lcc}
\hline Mechanical property & $x z$ plane & $y z$ plane \\
\hline $\bar{m}(\mathrm{~kg} / \mathrm{m})$ & 235664 & 235664 \\
$H(\mathrm{~m})$ & 144.24 & 144.24 \\
$T_{1}(\mathrm{~s})$ & 3.65 & 3.44 \\
$\gamma_{1}$ & 1.5708 & 1.9173 \\
$\alpha$ & $1 \times 10^{100}$ & 3.5 \\
$E I\left(\mathrm{~N} \cdot \mathrm{m}^{2}\right)$ & $1.2251 \times 10^{-186}$ & $5.8129 \times 10^{12}$ \\
$G A^{S}(\mathrm{~N})$ & $5.8885 \times 10^{9}$ & $3.4225 \times 10^{9}$ \\
\hline
\end{tabular}

dynamic response. For a time-domain inelastic analysis, maybe a possible solution could be to compute the elongation of the fundamental period (i.e., stiffness degradation) at each time step by using hysteresis loops. In this way, the stiffness matrix of the coupled system, $\left[K_{\mathrm{CSF}}\right]$, could be assembled at each time step from the new values of EI and $\mathrm{GA}^{S}$. However, further research related to the possibility of an extended CSF model capable of computing the inelastic response must be done. On the other hand, a linear elastic behavior can be considered acceptable when the passive energy dissipation devices are effective in controlling earthquake-induced vibrations.

An earthquake ground motion record is composed by three orthogonal components: one vertical component and two horizontal components. For earthquakes acting in two directions, the two horizontal components of the ground acceleration must be applied to each translational direction of the CSF model by independent time-domain dynamic analyses. The Mexico City building code classifies the soil of the Valley of Mexico as firm (i.e., hard rock), lakebed (i.e., high water content clay underlain by resistant sands), and transition (i.e., between firm soil and lakebed zone). Three different stations are considered for the Mexico City earthquake of September 19, 1985: the N90E component recorded at station Central-de-Abastos-Frigorífico (CDAF), the N58E component recorded at station Sismex-Viveros (SXVI), and the S90W component recorded at station Ciudad-Universitaria-Mesa-Vibradora (CUMV). The earthquake ground motion records related to Table 13 are 


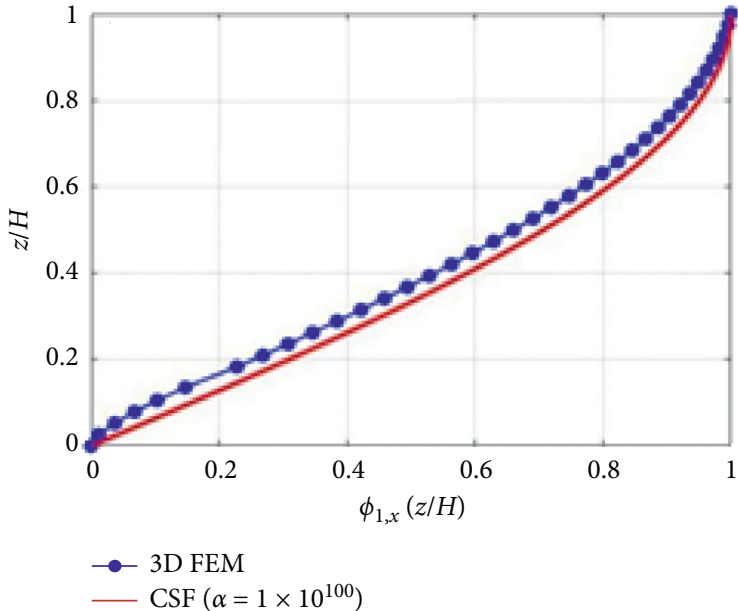

(a)

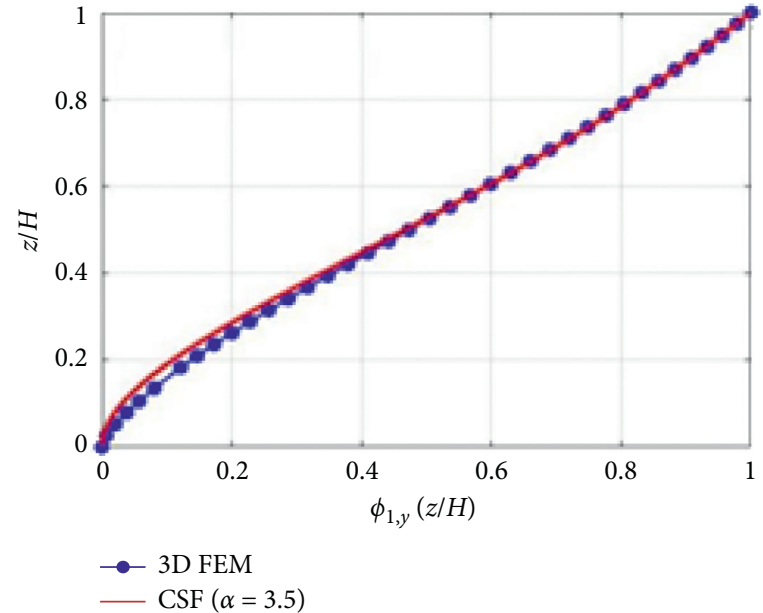

(b)

Figure 8: Mode shape of the first mode of vibration: 3D FEM vs. CSF model [55]. (a) $x z$ plane. (b) $y z$ plane.

TABLE 7: Periods and participating mass ratios of the fixed-base building: CSF model vs. 3D FEM [55].

\begin{tabular}{lccccccc}
\hline \multirow{2}{*}{ Mode } & \multicolumn{2}{c}{ Period (s) } & \multicolumn{3}{c}{ Participating mass ratio (\%) } \\
& \multicolumn{2}{c}{$x z$ plane } & \multicolumn{2}{c}{$y z$ plane } & \multicolumn{2}{c}{$x z$ plane } & CSF \\
1 & CSF & 3D FEM & CSF & 3D FEM & CSF & 3D FEM & 3D FEM \\
2 & 3.65 & 3.65 & 3.44 & 3.44 & 81.03 & 77.26 & 67.94 \\
3 & 1.22 & 1.25 & 0.89 & 0.98 & 8.98 & 8.86 & 13.17 \\
\hline
\end{tabular}

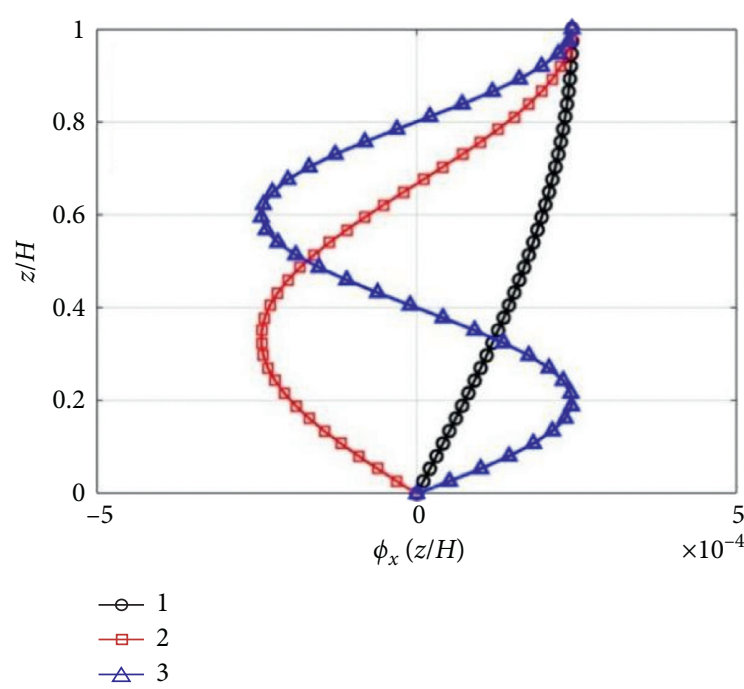

(a)

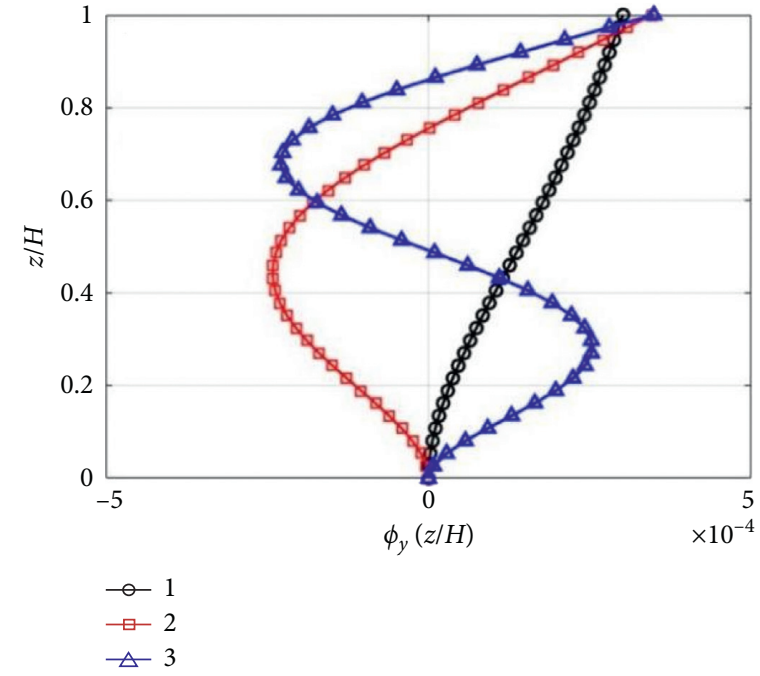

(b)

Figure 9: Mode shapes of the fixed-base building: CSF model without PDAs. (a) $x z$ plane. (b) $y z$ plane.

shown in Figure 10(a), whereas the elastic input energy spectra, related to a structural damping ratio of $5 \%$, are shown in Figure 10(b). Both Table 13 and Figure 10 clearly show that the soil type significantly modifies the duration, peak ground acceleration, and energy content of the earthquake ground motion records, particularly for the
CDAF station, where the seismic waves were significantly amplified by the geologic conditions of the lakebed zone. For the three seismic records, Table 14 shows that peak values of input energy are related to periods lower than $T_{x z, 1}=3.65 \mathrm{~s}$ and $T_{y z, 1}=3.44 \mathrm{~s}$. Therefore, PDAs could be less effective in controlling earthquake-induced vibrations because soil- 
TABLE 8: Dynamic properties of a TMD attached at $z_{\mathrm{PDA}}=H$.

\begin{tabular}{lcccccccc}
\hline Loading case and optimization criteria & Plane & $\mu$ & $T_{\mathrm{PDA}}(\mathrm{s})$ & $\xi_{\mathrm{PDA}}$ & $\begin{array}{c}m_{\mathrm{PDA}}(\mathrm{kg}) \\
\mathrm{N}\end{array}$ & $\begin{array}{c}k_{\mathrm{PDA}} \\
(\mathrm{N} / \mathrm{m})\end{array}$ & $\begin{array}{c}c_{\mathrm{PDA}} \\
(\mathrm{N} \mathrm{s} / \mathrm{m})\end{array}$ \\
\hline Harmonic base acceleration for minimum relative displacement & $x z$ & 0.0140 & 3.71 & 0.0722 & 237944 & 680961 & 58132 \\
amplitude of primary structure & $y z$ & 0.0276 & 3.56 & 0.1011 & 303848 & 946709 & 108403 \\
\hline Harmonic load for minimum relative acceleration amplitude of primary & $x z$ & 0.0141 & 3.68 & 0.0725 & 239644 & 700260 & 59367 \\
structure & $y z$ & 0.0281 & 3.49 & 0.1019 & 309353 & 1003833 & 113613 \\
\hline
\end{tabular}

TABLE 9: Geometry and dynamic properties of a C-TSD attached at $z_{\mathrm{PDA}}=H$.

\begin{tabular}{lcccc}
\hline Parameter & \multicolumn{2}{c}{ Seismic load } & & \multicolumn{2}{c}{ Along-wind load } \\
& $x z$ plane & $y z$ plane & $x z$ plane & 0.0141 \\
$\mu$ & 0.0140 & 0.0276 & 3.68 & 0.0281 \\
$T_{\mathrm{PDA}}(\mathrm{s})$ & 3.69 & 3.51 & 0.0324 & 3.49 \\
$\xi_{\mathrm{PDA}}(\mathrm{m})$ & 0.0323 & 0.0420 & 5 & 0.0421 \\
$h(\mathrm{~m})$ & 5 & 5 & 3.05 & 5 \\
$m_{\mathrm{PDA}}(\mathrm{kg})$ & 3.02 & 79600 & 72258 & 80125 \\
$k_{\mathrm{PDA}}(\mathrm{N} / \mathrm{m})$ & 71968 & 255630 & 210650 & 259010 \\
$c_{\mathrm{PDA}}(\mathrm{N} \mathrm{s} / \mathrm{m})$ & 208960 & 11978 & 7993.8 & 12133 \\
\hline
\end{tabular}

TABLE 10: Geometry and dynamic properties of a R-TSD attached at $z_{\mathrm{PDA}}=H$.

\begin{tabular}{lcccc}
\hline Parameter & Seismic load & & \multicolumn{2}{c}{ Along-wind load } \\
& $x z$ plane & $y z$ plane & $x z$ plane & 0.0141 \\
$\mu$ & 0.0140 & 0.0276 & 3.69 & 0.0281 \\
$T_{\mathrm{PDA}}(\mathrm{s})$ & 3.70 & 3.52 & 0.0448 & 3.51 \\
$\xi_{\mathrm{PDA}}(\mathrm{m})$ & 0.0448 & 0.0580 & 8.69 & 0.0581 \\
$b(\mathrm{~m})$ & 8.69 & 8.68 & 8.67 & 8.68 \\
$h(\mathrm{~m})$ & 8.71 & 8.69 & 3.18 & 4.10 \\
$m_{\mathrm{PDA}}(\mathrm{kg})$ & 3.14 & 4.03 & 138170 & 152340 \\
$k_{\mathrm{PDA}}(\mathrm{N} / \mathrm{m})$ & 138030 & 151530 & 400610 & 488150 \\
$c_{\mathrm{PDA}}(\mathrm{N} \mathrm{s} / \mathrm{m})$ & 398040 & 482800 & 21086 & 31691 \\
\hline
\end{tabular}

TABLE 11: Geometry and dynamic properties of a TWLD attached at $z_{\mathrm{PDA}}=H$.

\begin{tabular}{|c|c|c|c|c|}
\hline \multirow{2}{*}{ Parameter } & \multicolumn{2}{|c|}{ Seismic load } & \multicolumn{2}{|c|}{ Along-wind load } \\
\hline & $x z$ plane & $y z$ plane & $x z$ plane & $y z$ plane \\
\hline$\mu$ & 0.003 & 0.003 & 0.003 & 0.003 \\
\hline$T_{\mathrm{PDA}}(\mathrm{s})$ & 3.54 & 3.46 & 3.53 & 3.46 \\
\hline$\xi_{\mathrm{PDA}}$ & 0.0273 & 0.0274 & 0.0160 & 0.0218 \\
\hline$L_{h}(\mathrm{~m})$ & 3.60 & - & 3.62 & - \\
\hline$L_{w}(\mathrm{~m})$ & - & 6.82 & - & 6.80 \\
\hline$h(\mathrm{~m})$ & 2.02 & 2.02 & 2.01 & 2.01 \\
\hline$t(\mathrm{~m})$ & 1.20 & 1.20 & 1.21 & 1.21 \\
\hline$m_{\mathrm{PDA}}(\mathrm{kg})$ & 50988 & 32469 & 50988 & 32503 \\
\hline$k_{\mathrm{PDA}}(\mathrm{N} / \mathrm{m})$ & 160570 & 107240 & 161440 & 107480 \\
\hline$c_{\mathrm{PDA}}(\mathrm{N} \mathrm{s} / \mathrm{m})$ & 4949.2 & 3228 & 2896.6 & 2581.5 \\
\hline
\end{tabular}

building resonance is avoided for both orthogonal directions. For the purposes of this numerical example, the soilstructure interaction effects are neglected; that is, the same modes of vibration of the fixed-based 144-meter-tall building are considered for the three seismic records shown in Figure 10(a).

According to the geometry and dynamic properties specified in Tables 8-12, 15 and 16 show the periods and modal participating mass ratios of the building with a single
PDA when the primary structure is subjected to the horizontal ground accelerations shown in Figure 10(a).

Tables 15 and 16 show that if a total of $N_{\text {PDA }}$ PDAs are attached to the building, the first $N_{\mathrm{PDA}}$ modes of vibration will be under the influence of $N_{\text {PDA }}$ PDAs, and the $\left(N_{\mathrm{PDA}}+1\right)^{\text {th }}$ mode of vibration will actually be the first mode of the building [37]. For example, if a single PDA is attached to the building, the first mode will be related to the PDA vibration, the second mode will be related to the first 
TABLE 12: Geometry and dynamic properties of a PTMD attached at $z_{\mathrm{PDA}}=H$.

\begin{tabular}{lcccc}
\hline Parameter & \multicolumn{2}{c}{ Base acceleration } & & Force \\
& $x z$ plane & $y z$ plane & $x z$ plane & 0.0141 \\
$\mu$ & 0.0140 & 0.0276 & 3.69 & 0.0281 \\
$T_{\mathrm{PDA}}(\mathrm{s})$ & 3.71 & 3.56 & 0.0591 & 3.51 \\
$\xi_{\mathrm{PDA}}$ & 0.0589 & 0.0822 & 3.38 & 0.0829 \\
$l_{p}(\mathrm{~m})$ & 3.43 & 3.15 & 239640 & 3.07 \\
$m_{\mathrm{PDA}}(\mathrm{kg})$ & 237940 & 303850 & 695390 & 309350 \\
$k_{\mathrm{PDA}}(\mathrm{N} / \mathrm{m})$ & 680960 & 946710 & 48220 & 990120 \\
$c_{\mathrm{PDA}}(\mathrm{N} \mathrm{s} / \mathrm{m})$ & 47381 & 88205 & 91813 \\
\hline
\end{tabular}

Table 13: General characteristics of the Mexico City earthquake of September 19, 1985.

\begin{tabular}{lccccccc}
\hline Origin & $\begin{array}{c}\text { Surface-wave } \\
\text { magnitude }\end{array}$ & $\begin{array}{c}\text { Depth } \\
(\mathrm{km})\end{array}$ & Station & Soil type & $\begin{array}{c}\text { Epicentral distance } \\
(\mathrm{km})\end{array}$ & $\begin{array}{c}\text { Peak ground acceleration } \\
\left(\mathrm{m} / \mathrm{s}^{2}\right)\end{array}$ & $\begin{array}{c}\text { Duration } \\
(\mathrm{s})\end{array}$ \\
\hline \multirow{3}{*}{ Subduction } & \multirow{2}{*}{15} & & CDAF & Lakebed & 430 & 1.1749 \\
& \multirow{2}{*}{15} & & SXVI & Transition & 422 & 0.4163 & 143.19 \\
& & & CUMV & Firm & 419 & 0.3828 & 129.15 \\
\hline
\end{tabular}

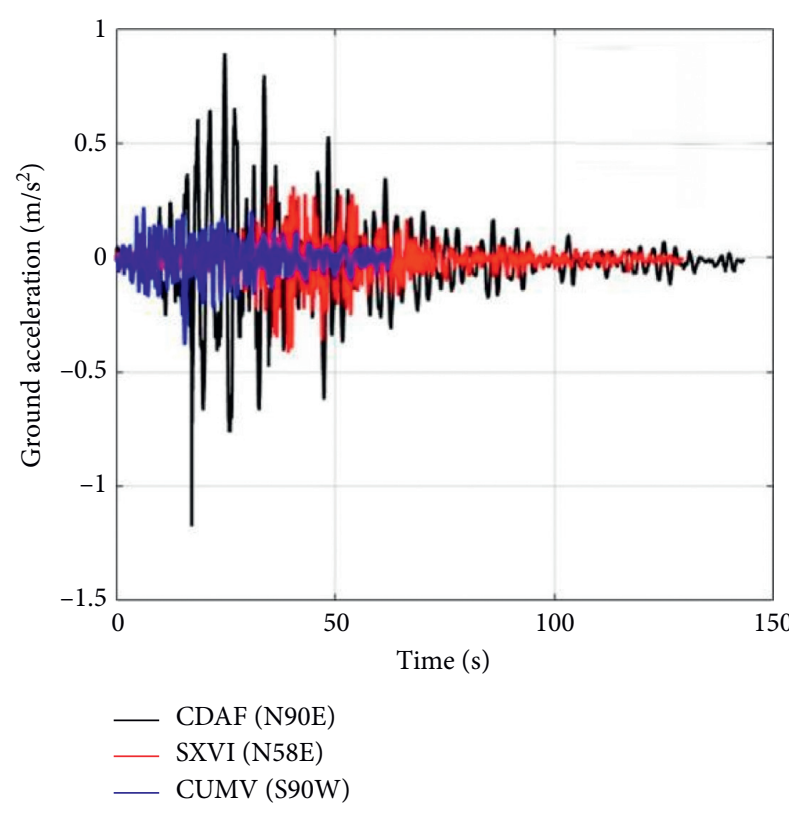

(a)

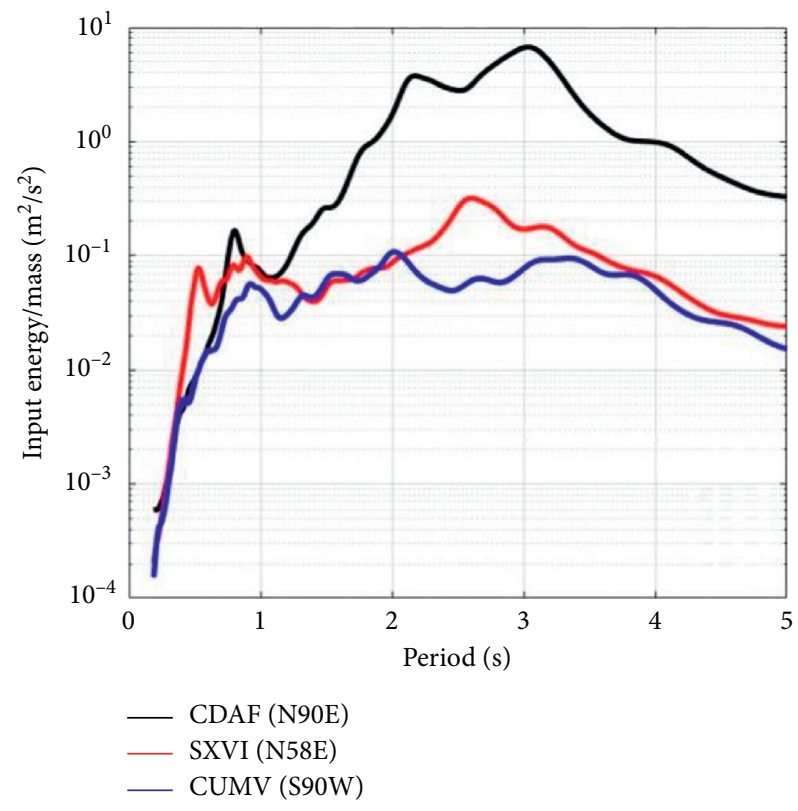

(b)

Figure 10: Mexico City earthquake of September 19, 1985. (a) Earthquake ground motion records. (b) Elastic input energy spectra.

TABLE 14: Elastic input energy of interest: Mexico City earthquake of September 19, 1985.

\begin{tabular}{|c|c|c|c|c|c|c|c|c|c|}
\hline Station & & CDAF & & & SXVI & & & CUMV & \\
\hline Period $(s)$ & 3.03 & 3.44 & 3.65 & 2.60 & 3.44 & 3.65 & 2.02 & 3.44 & 3.65 \\
\hline Input energy/mass $\left(\mathrm{m}^{2} / \mathrm{s}^{2}\right)$ & 6.6986 & 2.0964 & 1.2506 & 0.3186 & 0.1150 & 0.0885 & 0.1083 & 0.0897 & 0.0682 \\
\hline
\end{tabular}

mode without PDAs, and the third mode will be related to the second mode without PDAs, etc. For different lateral resisting systems, the structural mass of an equivalent SDOF system at $z_{\mathrm{PDA}}=H$ increases as the value of $\alpha$ increases, that is, $m_{\mathrm{SDOF}, x}=1.6996 \times 10^{7} \mathrm{~kg}$ and $m_{\mathrm{SDOF}, y}=1.1009 \times 10^{7} \mathrm{~kg}$. In a similar way, the participating mass ratio related to the first mode of vibration without PDAs also increases as the value of $\alpha$ increases, that is, $m_{\text {eff, } 1} / m_{T}=0.8103$ and $m_{\mathrm{eff}, 1} / m_{T}=0.6794$ for $x z$ plane and $y z$ plane, respectively.

For the five different PDAs shown in Tables 8-12, 36 time-history elastic analyses were carried out assuming that the building is subjected to the horizontal ground accelerations shown in Figure 10(a). Assuming a structural damping ratio of $5 \%$ and neglecting soil-structure 
TABle 15: Periods and participating mass ratios for $x z$ plane of the building with a single PDA: seismic load.

\begin{tabular}{lccccccc}
\hline \multirow{2}{*}{ Case } & \multicolumn{4}{c}{ Period (s) } & \multicolumn{4}{c}{ Participating mass ratio (\%) } \\
& Mode 1 & Mode 2 & Mode 3 & Mode 4 & Mode 1 & Mode 2 & Mode 3 \\
\hline No PDAs & 3.65 & 1.22 & 0.73 & 0.52 & 81.03 & 8.98 & 3.22 \\
TMD & 3.91 & 3.47 & 1.22 & 0.73 & 37.19 & 39.85 & 8.45 \\
C-TSD & 3.79 & 3.55 & 1.22 & 0.73 & 35.25 & 41.67 & 8.51 \\
R-TSD & 3.85 & 3.52 & 1.22 & 0.73 & 36.16 & 40.80 & 8.48 \\
TWLD & 3.71 & 3.48 & 1.22 & 0.73 & 58.96 & 17.95 & 8.03 \\
PTMD & 3.91 & 3.47 & 1.22 & 0.73 & 37.20 & 39.84 & 8.45 \\
\hline
\end{tabular}

TABLE 16: Periods and participating mass ratios for $y z$ plane of the building with a single PDA: seismic load.

\begin{tabular}{|c|c|c|c|c|c|c|c|c|}
\hline \multirow{2}{*}{ Case } & \multicolumn{4}{|c|}{ Period (s) } & \multicolumn{4}{|c|}{ Participating mass ratio (\%) } \\
\hline & Mode 1 & Mode 2 & Mode 3 & Mode 4 & Mode 1 & Mode 2 & Mode 3 & Mode 4 \\
\hline No PDAs & 3.44 & 0.89 & 0.38 & 0.21 & 67.94 & 13.17 & 5.71 & 3.10 \\
\hline TMD & 3.80 & 3.22 & 0.89 & 0.38 & 29.37 & 35.48 & 12.42 & 5.37 \\
\hline C-TSD & 3.62 & 3.32 & 0.89 & 0.38 & 26.29 & 38.31 & 12.53 & 5.41 \\
\hline R-TSD & 3.69 & 3.28 & 0.89 & 0.38 & 28.22 & 36.47 & 12.50 & 5.40 \\
\hline TWLD & 3.54 & 3.35 & 0.89 & 0.38 & 29.08 & 35.47 & 12.56 & 5.42 \\
\hline PTMD & 3.80 & 3.22 & 0.89 & 0.38 & 29.37 & 35.48 & 12.42 & 5.37 \\
\hline
\end{tabular}

interaction effects, the peak displacements and peak interstory drift ratios (IDR) are shown in Figures 11-14; whereas the peak values related to the critical storey are shown in Tables 17 and 18. Furthermore, Table 19 shows the peak values of both base shear force and base overturning moment, which were computed by the equivalent static load method [53].

According to Tables 17-19, all the PDAs are ineffective in vibration control for the CDAF and SXVI stations. According to Soto and Ruiz [56], the effectiveness of TMDs is higher for systems with small nonlinearity produced by small and moderate earthquakes, than for systems with high nonlinear behavior, generally associated with high-intensity motions. The ineffectiveness of vibration control of all PDAs in the CDAF and SXVI stations could be related to the highintensity motion despite the assumed linear elastic behavior of the CSF model. The seismic response of a linear elastic building subjected to the narrow-band long duration can be significantly reduced if a TMD is included on its top; however, this reduction does not always represent a real advantage for buildings with a period near the dominant of the soil, because for intense motions the maximum-in-time base shear ratio still results too high [57], e.g., the case for $2 \mathrm{~s}$ period buildings located on soft soil in the Valley of Mexico.

For CUMV station, all the PDAs are slightly more effective for the vibration control of the primary structure. Approximately a $6 \%$ reduction is achieved for peak displacements and peak internal forces at the base. For low-to moderate-intensity motion (e.g., CUMV station), the effectiveness of TMDs in vibration control of buildings with a period near the dominant of the soil (i.e., $2 \mathrm{~s}$ period building) can significantly increase as the value of $\mu$ increases (e.g., by using distributed multiple TMDs) [37]. However, larger values of $\mu$ are not possible when TLDs (C-TSD, R-TSD, TWLD) are attached to the 144-meter-tall building (see Tables 8-12). According to Tables 8-12, the same values of $\mu$ for four different kinds of PDAs (TMD, C-TSD, R-TSD, and PTMD) lead to different values of $m_{\mathrm{PDA}}$ and $\xi_{\mathrm{PDA}}$, that is, the PDA mass efficiency index, $\lambda$, of the liquid mass vibration absorbers leads to lower values of $m_{\mathrm{PDA}}$ and $\xi_{\mathrm{PDA}}$. Therefore, the solid mass vibration absorbers (i.e., TMD and PTMD) are slightly more effective in controlling the seismic response in CUMV station (see Tables 17 to 19 ).

According to Table 18, the damage index is usually expressed in terms of the peak interstory drift ratio. For $x z$ plane, the greatest damage is located at $z=0.22 \mathrm{H}$, $z=0.027 \mathrm{H}$ and $z=0.027 \mathrm{H}$ for CDAF, SXVI and CUMV stations, respectively; however, for the solid mass vibration absorbers (TMD and PTMD), the greatest damage in the CUMV station is located at $z=0.081 \mathrm{H}$. For $y z$ plane, the greatest damage is located at $z=0.51 H, z=0.68 H$, and $z=$ $0.43 H$ for CDAF, SXVI, and CUMV stations, respectively; however, for the solid mass vibration absorbers (TMD and PTMD), the greatest damage in the CUMV station is located at $z=0.59 H$. Therefore, the critical story depends not only on the value of $\alpha$ but also on the earthquake ground motion record and the equivalent parameters of the PDA.

The earthquake-induced vibrations shown in this section cannot be generalized because duration, peak ground acceleration, and energy content of earthquake ground motion records change depending on the epicentral distance, geologic conditions, and origin of the earthquake (e.g., local earthquakes, continental-plate earthquakes, normal-faulting earthquake, subduction earthquakes). In future works, the effectiveness of PDAs in controlling earthquake-induced vibrations will be studied using a flexible-base CSF model [58] subjected to several earthquake ground motion records.

5.2. Along-Wind Vibrations. The 144-meter-tall building is located in a suburban area with a roughness length of $0.3 \mathrm{~m}$. Assuming an annual probability of 0.1 , the mean wind 


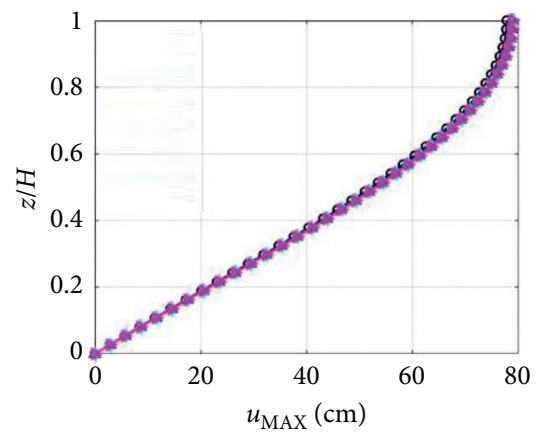

$\begin{array}{ll}\rightarrow \text { No PDAs } & \star \text { R-TSD } \\ \square \text { TMD } & \diamond \text { TWLD } \\ \triangle \text { C-TSD } & \rightarrow \text { PTMD }\end{array}$

(a)
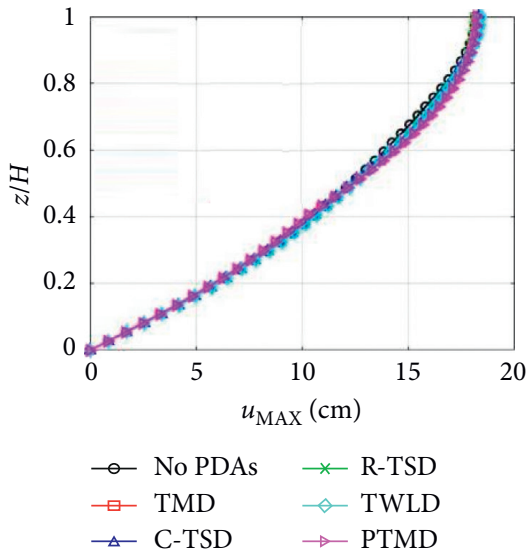

(b)

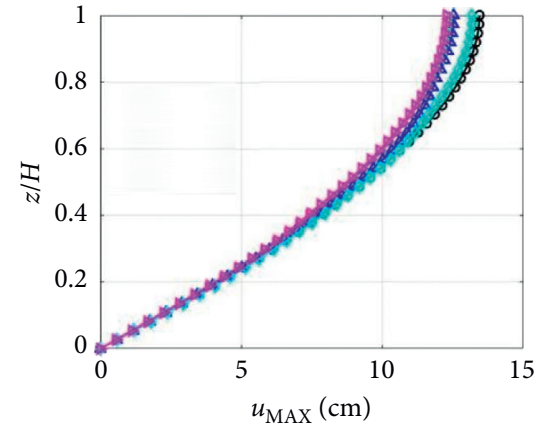

$\begin{array}{ll}\rightarrow \text { No PDAs } & \star \text { R-TSD } \\ \square \text { TMD } & \diamond \text { TWLD } \\ \triangle \text { C-TSD } & \rightarrow \text { PTMD }\end{array}$

(c)

FIGURE 11: Seismic peak displacements of the building: $x z$ plane. (a) CDAF. (b) SXVI. (c) CUMV.

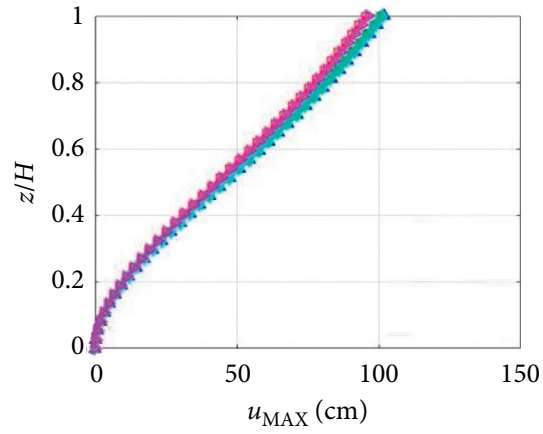

$\begin{array}{ll}\rightarrow \text { No PDAs } & \star \text { R-TSD } \\ \square \text { TMD } & \succ \text { TWLD } \\ \triangle \text { C-TSD } & \rightarrow \text { PTMD }\end{array}$

(a)

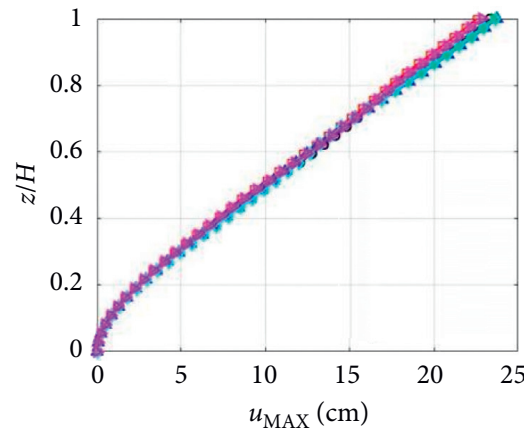

$\begin{array}{ll}\rightarrow \text { No PDAs } & \rightarrow \text { R-TSD } \\ \square \text { TMD } & \succ \text { TWLD } \\ \triangle \text { C-TSD } & \rightarrow \text { PTMD }\end{array}$

(b)
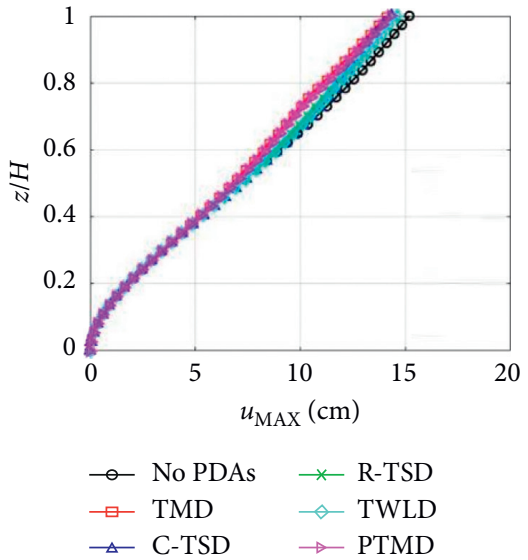

(c)

Figure 12: Seismic peak displacements of the building: $y z$ plane. (a) CDAF. (b) SXVI. (c) CUMV.

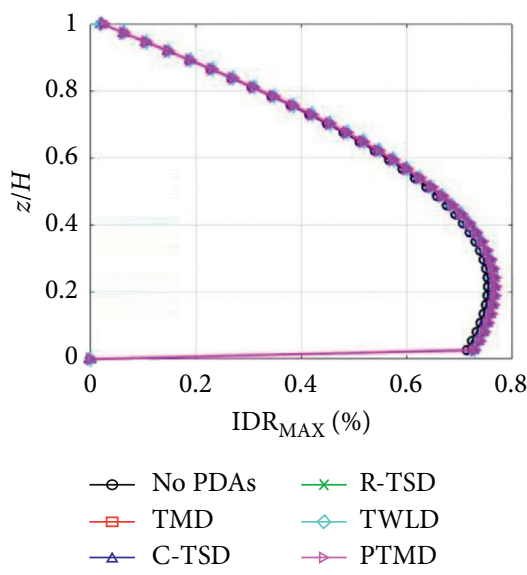

(a)

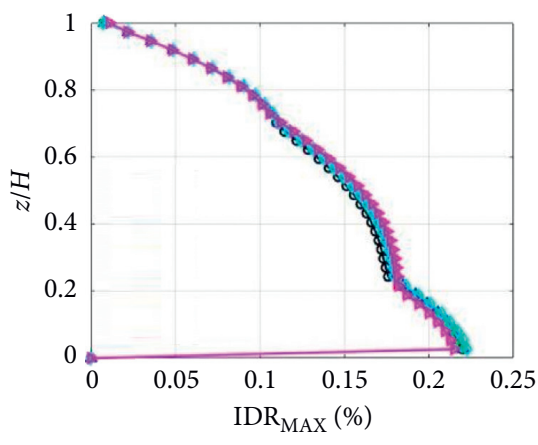

$\begin{array}{ll}\rightarrow \text { No PDAs } & \rightarrow \text { R-TSD } \\ \square \text { TMD } & \succ \text { TWLD } \\ \triangle \text { C-TSD } & \rightarrow \text { PTMD }\end{array}$

(b)

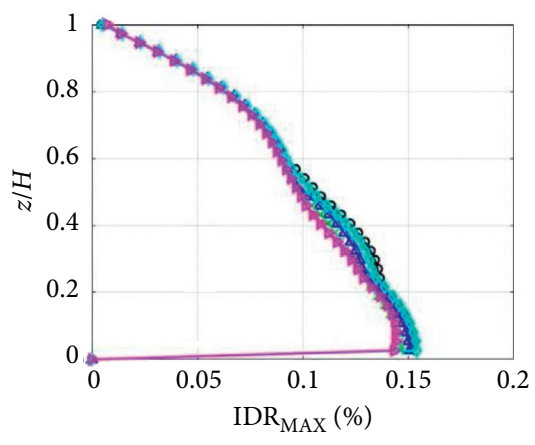

$\begin{array}{ll}\rightarrow \text { No PDAs } & * \text { R-TSD } \\ \square \text { TMD } & \succ \text { TWLD }\end{array}$

(c)

FIGURE 13: Seismic peak interstory drift ratios of the building: $x z$ plane. (a) CDAF. (b) SXVI. (c) CUMV.

velocity at $10 \mathrm{~m}$ height is equal to $15.02 \mathrm{~m} / \mathrm{s}$ [59]. In a wind field, the drag force at the $j$ th story is given by the following equation:

$$
F_{j}(t)=\frac{1}{2} \rho_{a} A_{j} C_{D}\left[\bar{U}\left(z_{j}\right)+u\left(z_{j}, t\right)\right]^{2}
$$




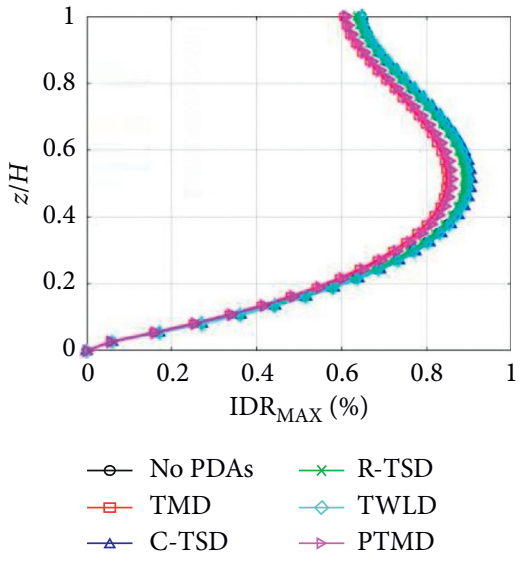

(a)

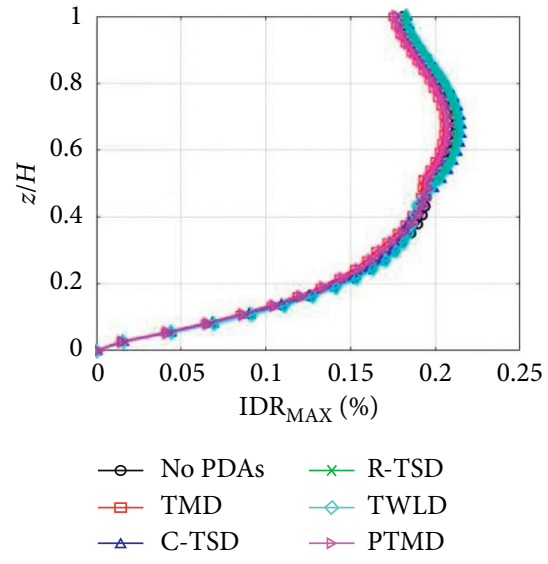

(b)

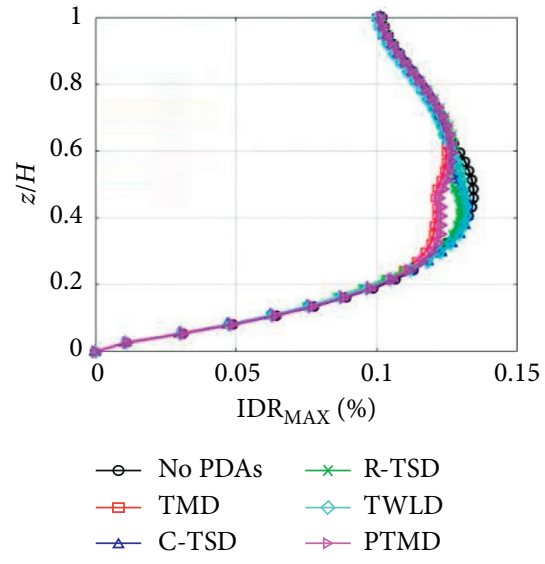

(c)

FIGURE 14: Seismic peak interstory drift ratios of the building: $y z$ plane. (a) CDAF. (b) SXVI. (c) CUMV.

TABLe 17: Peak seismic displacement $[\mathrm{cm}]$ at $z=H$.

\begin{tabular}{lccccccc}
\hline Plane & Station & No PDAs & TMD & C-TSD & R-TSD & TWLD & PTMD \\
\hline \multirow{3}{*}{$x z$} & CDAF & 77.72 & 78.55 & 78.72 & 78.69 & 78.92 & 78.81 \\
& SXVI & 18.14 & 18.11 & 18.30 & 18.08 & 18.42 & 18.21 \\
& CUMV & 13.44 & 12.28 & 12.52 & 12.35 & 13.17 & 12.27 \\
\hline \multirow{3}{*}{$y z$} & CDAF & 101.21 & 95.29 & 101.98 & 100.31 & 101.51 & 96.54 \\
& SXVI & 23.32 & 22.56 & 23.75 & 23.53 & 23.66 & 22.87 \\
& CUMV & 15.18 & 14.07 & 14.33 & 14.42 & 14.58 \\
\hline
\end{tabular}

TABLe 18: Peak interstory drift ratio at the critical story.

\begin{tabular}{|c|c|c|c|c|c|}
\hline \multirow{2}{*}{ Station } & \multirow{2}{*}{ Case } & \multicolumn{2}{|r|}{$x z$ plane } & \multicolumn{2}{|r|}{$y z$ plane } \\
\hline & & $z / H$ & Peak interstory drift ratio (\%) & $z / H$ & Peak interstory drift ratio (\%) \\
\hline \multirow{6}{*}{ CDAF } & No PDAs & 0.22 & 0.7542 & 0.51 & 0.8968 \\
\hline & TMD & 0.22 & 0.7644 & 0.51 & 0.8468 \\
\hline & C-TSD & 0.22 & 0.7644 & 0.51 & 0.9049 \\
\hline & R-TSD & 0.22 & 0.7647 & 0.51 & 0.8907 \\
\hline & TWLD & 0.22 & 0.7672 & 0.51 & 0.9002 \\
\hline & PTMD & 0.22 & 0.7669 & 0.51 & 0.8584 \\
\hline \multirow{6}{*}{ SXVI } & No PDAs & 0.027 & 0.2198 & 0.68 & 0.2113 \\
\hline & TMD & 0.027 & 0.2147 & 0.68 & 0.2050 \\
\hline & C-TSD & 0.027 & 0.2204 & 0.68 & 0.2147 \\
\hline & R-TSD & 0.027 & 0.2176 & 0.68 & 0.2129 \\
\hline & TWLD & 0.027 & 0.2226 & 0.68 & 0.2140 \\
\hline & PTMD & 0.027 & 0.2148 & 0.68 & 0.2075 \\
\hline \multirow{6}{*}{ CUMV } & No PDAs & 0.027 & 0.1536 & 0.46 & 0.1344 \\
\hline & TMD & 0.081 & 0.1439 & 0.59 & 0.1247 \\
\hline & C-TSD & 0.027 & 0.1503 & 0.43 & 0.1322 \\
\hline & R-TSD & 0.027 & 0.1461 & 0.43 & 0.1297 \\
\hline & TWLD & 0.027 & 0.1541 & 0.43 & 0.1319 \\
\hline & PTMD & 0.081 & 0.1443 & 0.59 & 0.1267 \\
\hline
\end{tabular}

where $\rho_{a}$ is the air density; $A_{j}$ is the projected area of the $j$ th story; $C_{D}$ is the drag coefficient, which was assumed as equal to 1.1 and 1.45 for $x z$ plane and $y z$ plane, respectively [59]; $\bar{U}\left(z_{j}\right)$ is the mean wind velocity at $z_{j}$; and $u\left(z_{j}, t\right)$ is the fluctuating part of the wind field, which can be treated mathematically as a stationary stochastic process with a zero mean value. Assuming the Solari spectrum [60], the fluctuating component was computed by using the spectral representation technique [61]. According to equation (53), the simulated drag forces for the building are shown in Figure 15.

For wind engineering, the total damping ratio is composed of the structural part and the aerodynamic part, where the aerodynamic damping is caused by the interaction between the motion of a structure and motion of the air around it [62-64]. The aerodynamic damping increases the total 
TABLE 19: Seismic peak values for the internal forces at the base.

\begin{tabular}{|c|c|c|c|c|c|}
\hline \multirow[t]{2}{*}{ Station } & \multirow[t]{2}{*}{ Case } & \multicolumn{2}{|c|}{ Base shear force $(\mathrm{MN})$} & \multicolumn{2}{|c|}{$\begin{array}{l}\text { Base overturning moment } \\
(\mathrm{GN} \mathrm{m})\end{array}$} \\
\hline & & $x z$ plane & $y z$ plane & $x z$ plane & $y z$ plane \\
\hline \multirow{6}{*}{ CDAF } & No PDAs & 42.051 & 47.731 & 4.5766 & 5.2590 \\
\hline & TMD & 43.063 & 44.254 & 4.6588 & 4.9498 \\
\hline & C-TSD & 43.060 & 47.654 & 4.6630 & 5.3189 \\
\hline & R-TSD & 43.088 & 45.873 & 4.6473 & 5.2067 \\
\hline & TWLD & 43.263 & 47.828 & 4.6798 & 5.2915 \\
\hline & PTMD & 43.232 & 45.119 & 4.6726 & 5.0238 \\
\hline \multirow{6}{*}{ SXVI } & No PDAs & 13.099 & 14.283 & 1.065 & 1.1675 \\
\hline & TMD & 12.818 & 13.572 & 1.0681 & 1.122 \\
\hline & C-TSD & 13.148 & 14.081 & 1.0747 & 1.138 \\
\hline & R-TSD & 12.988 & 13.748 & 1.0612 & 1.1362 \\
\hline & TWLD & 13.266 & 14.299 & 1.0816 & 1.1482 \\
\hline & PTMD & 12.827 & 13.776 & 1.0733 & 1.1425 \\
\hline \multirow{6}{*}{ CUMV } & No PDAs & 9.0401 & 10.64 & 0.7935 & 0.8227 \\
\hline & TMD & 8.4385 & 10.338 & 0.7298 & 0.7466 \\
\hline & C-TSD & 8.8659 & 10.06 & 0.7408 & 0.7997 \\
\hline & R-TSD & 8.622 & 10.287 & 0.7308 & 0.7797 \\
\hline & TWLD & 9.0824 & 10.43 & 0.7773 & 0.7994 \\
\hline & PTMD & 8.4015 & 10.495 & 0.7289 & 0.7622 \\
\hline
\end{tabular}

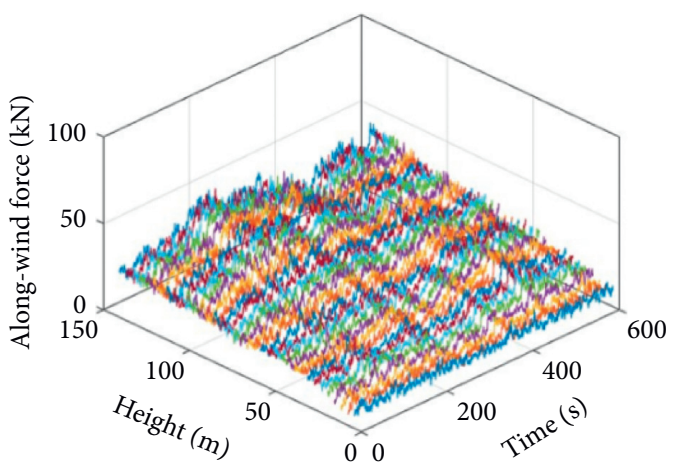

(a)

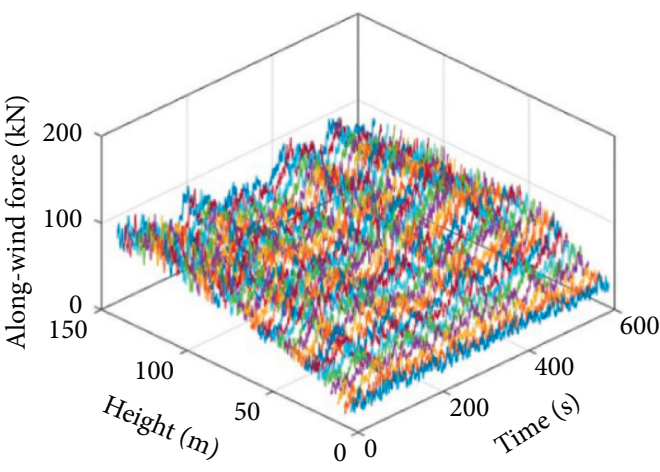

(b)

FIGURE 15: Along-wind forces for the building. (a) $x z$ plane. (b) $y z$ plane.

damping for along-wind vibration depending on the wind profile and the fundamental mode of vibration of the building [63], whereas the aerodynamic damping could be negative for across-wind vibrations [64]. In this paper, the aerodynamic contribution was neglected because the main aim is the unification of different PDAs by using a CSF model. The structural part of the damping ratio depends not only on the type of structural material but also on the intensity of the motion, which is why structural damping ratios are usually lower in wind engineering, particularly for the assessment of the serviceability limit state. According to Tamura and Kareem [62], the structural damping ratio of 100-200-meter-tall buildings under wind loads is approximately equal to $1 \%$.

For the five different PDAs shown in Tables 8-12, 12 time-history elastic analyses were carried out, assuming that the building is subjected to the along-wind forces shown in Figure 15. Assuming a structural damping ratio of $1 \%$ and neglecting soil-structure interaction effects, the peak displacements are shown in Figure 16, whereas Table 20 shows the peak values of the internal forces at the base, which were computed by the equivalent static load method [53].

Generally speaking, Figure 16 shows that the five different PDAs are ineffective in controlling the along-wind peak lateral displacements of the building in both translational directions. Figure 16(a) shows that the five different PDAs are slightly more effective in controlling the peak lateral displacements in $x z$ plane. Consequently, Table 20 shows low effectiveness of PDAs in controlling both base shear force and base overturning moment.

The RMS accelerations are usually used to assess the serviceability limit state, which is why these are shown instead of the peak accelerations. The along-wind RMS accelerations are shown in Figure 17, where the rooftop RMS accelerations are shown in Table 21.

As was expected, Figure 17 shows a great effectiveness of the five different PDAs in controlling along-wind RMS 


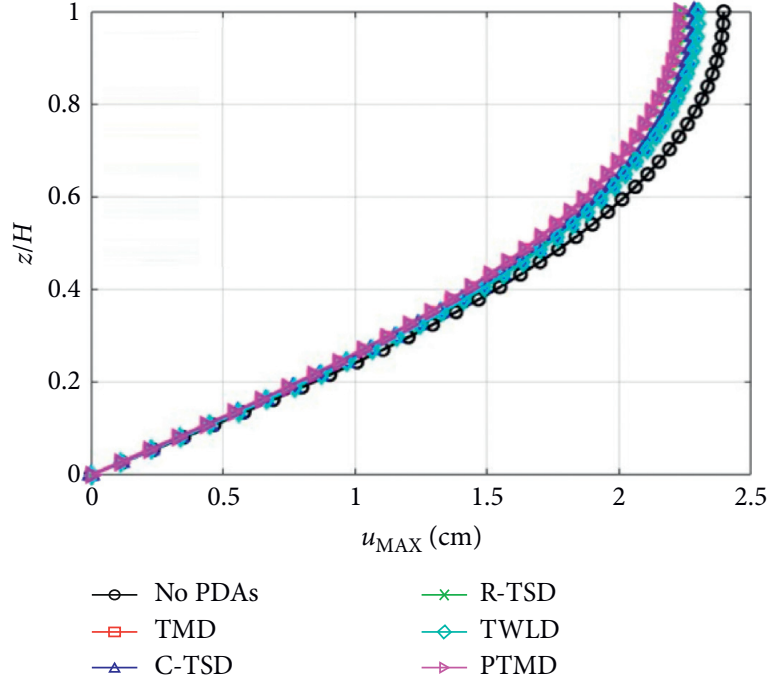

(a)

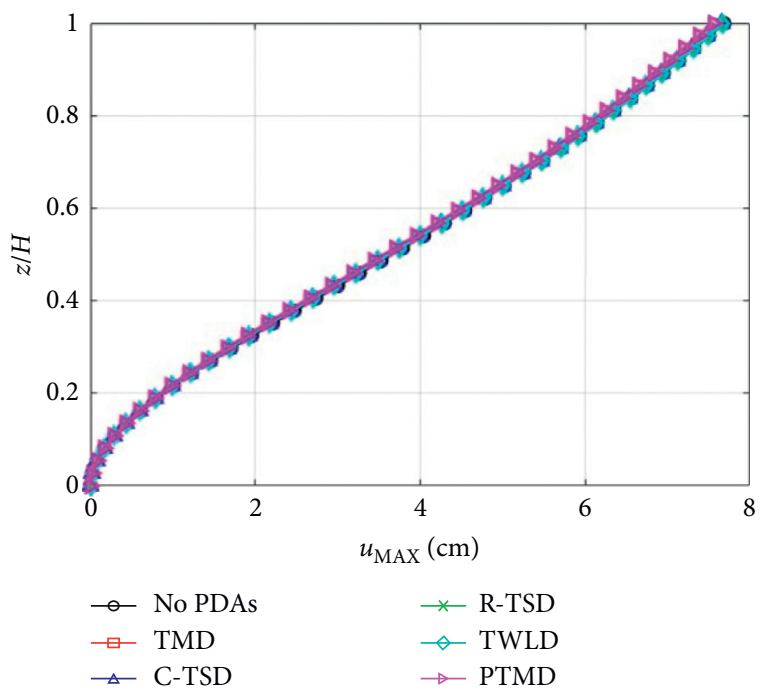

(b)

Figure 16: Along-wind peak displacements of the building. (a) $x z$ plane. (b) $y z$ plane.

TABLE 20: Along-wind peak values for the internal forces at the base.

\begin{tabular}{lcccc}
\hline \multirow{2}{*}{ Case } & \multicolumn{2}{c}{ Base shear force $(\mathrm{MN})$} & \multicolumn{2}{c}{ Base overturning moment $(\mathrm{GN}$ m) } \\
& $x z$ plane & $y z$ plane & $x z$ plane & 0.1411 \\
No PDAs & 1.7811 & 4.600 & 0.1312 & 0.4202 \\
TMD & 1.6624 & 4.5055 & 0.1345 & 0.4141 \\
C-TSD & 1.7091 & 4.5427 & 0.1311 & 0.4187 \\
R-TSD & 1.6661 & 4.5310 & 0.1352 & 0.4169 \\
TWLD & 1.7177 & 4.5490 & 0.1311 & 0.4195 \\
PTMD & 1.6625 & 4.5012 & & 0.4123 \\
\hline
\end{tabular}

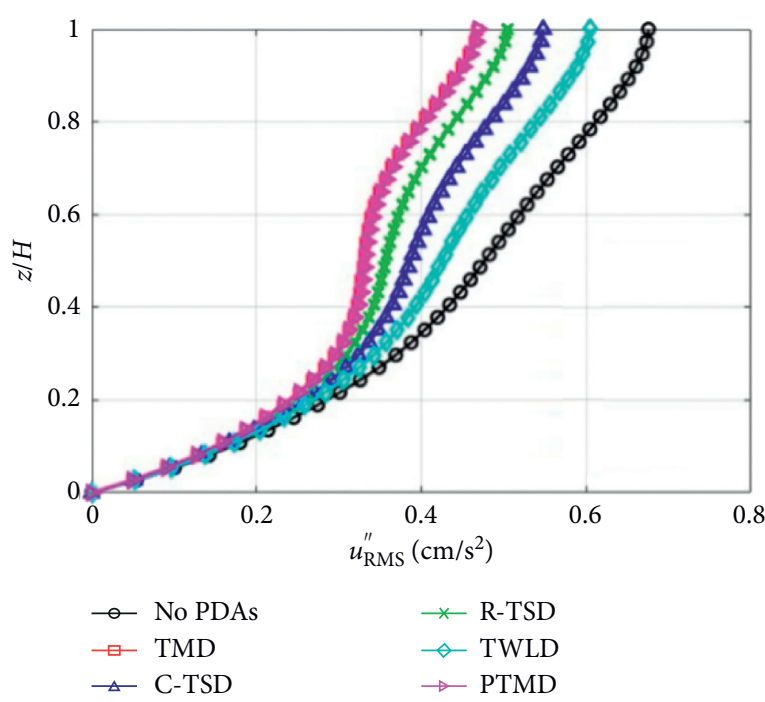

(a)

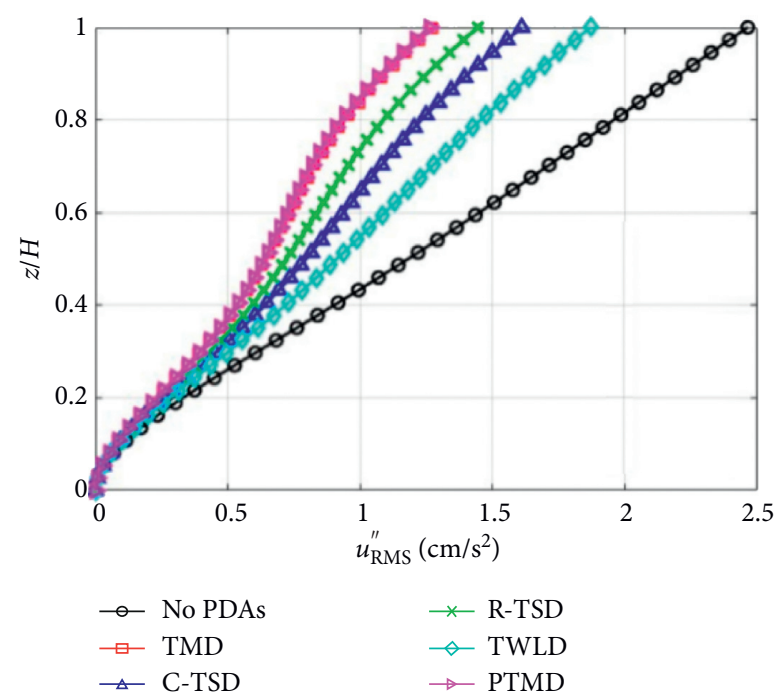

(b)

Figure 17: Along-wind RMS accelerations of the building. (a) $x z$ plane. (b) $y z$ plane.

accelerations of the building. According to Tables 8-12, values of $\mu$ are the same in each plane for TMD, R-TSD, C-TSD, and PTMD cases. Generally speaking, solid mass vibration absorbers (TMD and PTMD) are more effective in vibration control of RMS accelerations than tuned sloshing dampers (C-TSD and R-TSD) because the mass efficiency 
TABLe 21: Along-wind RMS accelerations at $z=H$.

\begin{tabular}{lccccccc}
\hline RMS & Plane & No PDAs & TMD & C-TSD & R-TSD & TWLD & PTMD \\
\hline \multirow{2}{*}{ Acceleration (milli-g) } & $x z$ & 0.6889 & 0.4761 & 0.5586 & 0.5144 & 0.6165 & 0.4781 \\
& $y z$ & 2.5124 & 1.2987 & 1.6417 & 1.4731 & 1.9075 & 1.2861 \\
\hline \multirow{2}{*}{ Reduction (\%) } & $x z$ & - & 30.88 & 18.92 & 25.33 & 10.51 \\
& $y z$ & - & 48.31 & 34.65 & 41.37 & 24.08 & 48.59 \\
& & & &
\end{tabular}

index is equal to $100 \%$ for solid mass vibration absorbers. For the solid mass vibration absorbers, the RMS value of acceleration response at the rooftop is reduced by $31 \%$ and $49 \%$ in $x z$ plane and $y z$ plane, respectively.

As it was previously mentioned, when a TSD is subjected to small amplitude excitations such as wind vibrations, the fundamental sloshing mode of a TSD is practically the only one that is excited. For this reason, and because of the highly periodic nature of wind excitation, TSDs are well suited to reduce structural motion due to wind [41]. Both TSDs achieve a great effectiveness in vibration control even though the mass efficiency index is less than $100 \%$; in fact, C-TSDs and R-TSDs achieve approximately $67 \%$ and $84 \%$ of the vibration control effectiveness of a TMD, respectively. Thereby, Figure 5 and Table 21 show that R-TSDs could be more effective in the vibration of RMS accelerations than C-TSDs; furthermore, a R-TSD is a more versatile device because it is able to be tuned to both translational directions by changing the dimensions of the tank. Unlike solid mass vibration absorbers (TMD and PTMD), tuned sloshing dampers offer the following benefits: low initial cost, easy and inexpensive installation, little to no maintenance, use in retrofit cases, and ease to design, among others.

According to Table 21, the TWLD was the least effective PDA in vibration control; however, the along-wind accelerations were significantly reduced even though the related values of $\mu$ are low in both translational directions (i.e., $\mu=0.003$ ). For a TWLD, the participation of the liquid is always greater in the TLCD direction; therefore, the values of $m_{\mathrm{PDA}}$ and $\xi_{\mathrm{PDA}}$ are lower in the TSD direction. However, the RMS value of acceleration response at the rooftop is reduced by $10.51 \%$ and $24.08 \%$ in TLCD direction ( $x z$ plane) and TSD direction ( $y z$ plane), respectively; this demonstrates that the vibration control increases at upper stories for flexural-type deformations (see Figure 4). In fact, this particular behaviour is achieved with all kinds of PDAs attached at the rooftop level; that is, the effectiveness in vibration control of RMS accelerations increases as the value of $\alpha$ decreases (see Figure 4(d)).

In future works, the effectiveness of PDAs in controlling wind-induced vibrations will be studied using a flexible-base CSF model [58] subjected to both along-wind and acrosswind forces.

\section{Conclusions}

A fixed-base coupled shear flexural (CSF) discrete model with TMDs is used to unify the design procedure of five different types of passive dynamic absorbers (PDAs): tuned mass damper (TMD), circular tuned sloshing damper (C-
TSD), rectangular tuned sloshing damper (R-TSD), twoway liquid damper (TWLD), and pendulum tuned mass damper (PTMD). By modifying the nondimensional lateral stiffness ratio, the CSF model can consider lateral deformations varying from those of a flexural cantilever beam to those of a shear cantilever beam. The unified model was applied to a 144-meter-tall building located in the Valley of Mexico, which was subjected to both seismic and alongwind loads. Accordingly, the following conclusions were obtained:

(a) For the first mode of vibration, the structural mass of an equivalent SDOF system at lower stories increases as the nondimensional lateral stiffness ratio decreases; on the contrary, for upper stories, it increases as the nondimensional lateral stiffness ratio increases. Therefore, if a single PDA attached at the rooftop level is tuned to the first mode of vibration, the maximum possible value of the mass efficiency index of the PDA increases as the nondimensional lateral stiffness ratio decreases. Furthermore, the mass efficiency index of the PDA also increases as the fundamental period of vibration of the building increases. Generally speaking, there is an increase in the vibration control effectiveness of PDAs for highrise buildings that deform as pure flexural beams.

(b) For the second mode of vibration, the PDA/SDOF nondimensional mass ratio increases as the nondimensional lateral stiffness ratio increases when a single PDA is attached in the middle stories, whereas for the third mode of vibration, the PDA/SDOF nondimensional mass ratio increases as the nondimensional lateral stiffness ratio decreases when a single PDA is attached in the middle stories. For both the second and third mode of vibration, the PDA/ SDOF nondimensional mass ratio increases as the nondimensional lateral stiffness ratio decreases, when a single PDA is attached at the rooftop level. Furthermore, for higher modes of vibration, the PDA/SDOF nondimensional mass ratio increases as the height of the attachment point of the PDA increases. Thus, a single PDA installed at the rooftop level could be more effective for multimode control than an equal-mass PDA installed at lower stories.

(c) For the same depth ratios, the mass efficiency index and the equivalent TMD mass of a TSD are greater for a rectangular container even though the total liquid mass is greater for a circular container. Therefore, a R-TSD could be a better option for vibration control than a C-TSD. Furthermore, a $\mathrm{R}-\mathrm{TSD}$ is a more versatile device because it is able to 
be tuned to both orthogonal directions by changing the dimensions of the tank. Wave motions in shallow-water TSDs are generally complex due to strong nonlinearities such as wave breaking; however, shallow-water TSDs provide high damping of liquid sloshing and an efficient moving mass.

(d) For earthquake-induced vibrations, the location of the peak interstory drift ratio could depend not only on the value of the nondimensional lateral stiffness ratio but also on the features of the earthquake ground motion record and the equivalent parameters of the PDA. Particularly, the location of the peak interstory drift ratio changed at the CUMV station for the specific case of the solid mass vibration absorbers (TMD and PTMD). However, further research is needed in this regard.

(e) For along-wind vibrations, the five different PDAs (TMD, C-TSD, R-TSD, TWLD, and PTMD) showed great effectiveness in controlling RMS accelerations. For the same values of the PDA/SDOF nondimensional mass ratios, solid mass vibration absorbers (TMD and PTMD) were more effective in vibration control of RMS accelerations than tuned sloshing dampers (C-TSD and R-TSD) because the mass efficiency index is equal to $100 \%$ for solid mass vibration absorbers. However, tuned sloshing dampers offer the following benefits: low initial cost, easy and inexpensive installation, little to no maintenance, use in retrofit cases, and ease to design, among others. The TWLD was the least effective PDA in vibration control. However, the along-wind accelerations were significantly reduced even though the maximum possible value of the PDA/SDOF nondimensional mass ratio was lower in both orthogonal directions.

(f) The attachment of uniformly distributed PDAs could be related to great effectiveness in controlling the dynamic response compared to a single PDA attached at the rooftop. However, it is highly recommended to use uniformly distributed PDAs in taller buildings in order to guarantee both a real solution and a possible geometry for the devices, particularly when TLDs are used to dissipate input energy.

(g) Literature features several formulas for optimum tuning conditions of PDAs; however, these formulas are not related to different lateral resisting systems. For this reason, these formulas are not the best option to optimize the passive vibration control in medium-rise to high-rise buildings, where the flexural deformation is as significant as the shear deformation.

\section{Data Availability}

The authors confirm that the data supporting the findings of this study are available within the article.

\section{Conflicts of Interest}

The authors declare that they have no conflicts of interest.

\section{Acknowledgments}

The authors would like to acknowledge CONACYT-Becas México for financially supporting the second author in conducting doctoral studies at Universidad Nacional Autónoma de México under the supervision of the first author. The authors also wish to thank Universidad Nacional Autónoma de México and Universidad Michoacana de San Nicolás de Hidalgo.

\section{References}

[1] R. Rahgozar, H. Safari, and P. Kaviani, "Free vibration of tall buildings using Timoshenko beams with variable cross-section," in Structures Under Shock and Impact VIII, N. Jones and C. A. Brebbia, Eds., WIT Press, Southampton, UK, 2004.

[2] E. Miranda and S. Taghavi, "Approximate floor acceleration demands in multistory buildings. I: formulation," Journal of Structural Engineering, vol. 131, no. 2, pp. 203-211, 2005.

[3] C. L. Dym and H. E. Williams, "Estimating fundamental frequencies of tall buildings," Journal of Structural Engineering, vol. 133, no. 10, pp. 1479-1483, 2007.

[4] S. Y. Chu, T. T. Soong, and A. M. Reinhorn, Active, Hybrid, and Semi-active Structural Control: A Design and Implementation Handbook, Wiley, New York, NY, USA, 2005.

[5] C. H. Chang and T. T. Soong, "Structural control using active tuned mass dampers," Journal of the Engineering Mechanics Division, vol. 106, no. 6, pp. 1091-1098, 1980.

[6] S. Elias and V. Matsagar, "Research developments in vibration control of structures using passive tuned mass dampers," Annual Reviews in Control, vol. 44, pp. 129-156, 2017.

[7] D. De Domenico, G. Ricciardi, and I. Takewaki, "Design strategies of viscous dampers for seismic protection of building structures: a review," Soil Dynamics and Earthquake Engineering, vol. 118, pp. 144-165, 2019.

[8] M. D. Symans and M. C. Constantinou, "Semi-active control systems for seismic protection of structures: a state-of-the-art review," Engineering Structures, vol. 21, no. 6, pp. 469-487, 1999.

[9] M. H. Stanikzai, S. Elias, V. A. Matsagar, and A. K. Jain, "Seismic response control of base-isolated buildings using multiple tuned mass dampers," The Structural Design of Tall and Special Buildings, vol. 28, no. 3, Article ID e1576, 2018.

[10] R. Rabiee and Y. Chae, "Adaptive base isolation system to achieve structural resiliency under both short- and long-period earthquake ground motions," Journal of Intelligent Material Systems and Structures, vol. 30, no. 1, pp. 1-16, 2019.

[11] A. D. Matteo, T. Furtmüller, C. Adam, and A. Pirrotta, "Optimal design of tuned liquid column dampers for seismic response control of base-isolated structures," Acta Mechanica, vol. 229, pp. 437-454, 2018.

[12] P. Gao, C. Xiang, H. Liu, and H. Zhou, "Reducing variable frequency vibrations in a powertrain system with an adaptive tuned vibration absorber group," Journal of Sound and Vibration, vol. 425, pp. 82-101, 2018.

[13] M. H. Stanikzai, S. Elias, and R. Rupakhety, "Seismic response mitigation of base-isolated buildings," Applied Sciences, vol. 10, no. 4, Article ID 1230, 2020. 
[14] A. Di Matteo, C. Masnata, and A. Pirrotta, "Hybrid passive control strategies for reducing the displacements at the base of seismic isolated structures," Frontiers in Built Environment, vol. 5, no. 132, pp. 1-13, 2019.

[15] J. P. Den Hartog, Mechanical Vibration, McGraw-Hill, New York, NY, USA, 1956.

[16] G. B. Warburton and E. O. Ayorinde, "Optimum absorber parameters for simple systems," Earthquake Engineering \& Structural Dynamics, vol. 8, no. 3, pp. 197-217, 1980.

[17] F. Sadek, B. Mohraz, A. W. Taylor, and R. M. Chung, "A method of estimating the parameters of tuned mass dampers for seismic applications," Earthquake Engineering and Structural Dynamics, vol. 26, no. 6, pp. 617-663, 1998.

[18] A. Kareem, "Reduction of wind induced motion utilizing a tuned sloshing damper," Journal of Wind Engineering and Industrial Aerodynamics, vol. 36, no. 2, pp. 725-737, 1990.

[19] C. C. Chang and M. Gu, "Suppression of vortex-excited vibration of tall buildings using tuned liquid dampers," Journal of Wind Engineering and Industrial Aerodynamics, vol. 83, no. 1-3, pp. 225-237, 1999.

[20] J.-C. Wu, M.-H. Shih, Y.-Y. Lin, and Y.-C. Shen, "Design guidelines for tuned liquid column damper for structures responding to wind," Engineering Structures, vol. 27, no. 13, pp. 1893-1905, 2005.

[21] M. J. Tait, "Modelling and preliminary design of a structureTLD system," Engineering Structures, vol. 30, no. 10, pp. 2644-2655, 2008.

[22] S.-K. Lee, K.-W. Min, and H.-R. Lee, "Parameter identification of new bidirectional tuned liquid column and sloshing dampers," Journal of Sound and Vibration, vol. 330, no. 7, pp. 1312-1327, 2011.

[23] K.-W. Min, J. Kim, and H.-R. Lee, "A design procedure of two-way liquid dampers for attenuation of wind-induced responses of tall buildings," Journal of Wind Engineering and Industrial Aerodynamics, vol. 129, pp. 22-30, 2014.

[24] L. Rozas, R. L. Boroschek, A. Tamburrino, and M. Rojas, “A bidirectional tuned liquid column damper for reducing the seismic response of buildings," Structural Control and Health Monitoring, vol. 23, no. 4, pp. 621-640, 2016.

[25] M. P. Sacks and J. C. Swallow, "Tuned mass dampers for towers and buildings," in Proceedings of the Symposium on Structural Engineering in Natural Hazards Mitigation, pp. 640-645, Irvine, CA, USA, 1993.

[26] R. R. Gerges and B. J. Vickery, "Optimum design of pendulum-type tuned mass dampers," The Structural Design of Tall and Special Buildings, vol. 14, no. 4, pp. 353-368, 2005.

[27] Z. Shu, S. Li, X. Sun, and M. He, "Performance-based seismic design of a pendulum tuned mass damper system," Journal of Earthquake Engineering, vol. 23, no. 2, pp. 334-355, 2019.

[28] C. C. Chang and W. L. Qu, "Unified dynamic absorber design formulas for wind-induced vibration control of tall buildings," The Structural Design of Tall Buildings, vol. 7, no. 2, pp. 147-166, 1998.

[29] C. C. Chang, "Mass dampers and their optimal designs for building vibration control," Engineering Structures, vol. 21, no. 5, pp. 454-463, 1999.

[30] F. Ricciardelli, "A linear model for structures with tuned mass dampers," Wind and Structures, vol. 2, no. 3, pp. 151-171, 1999.

[31] L. Min-Yi, C. Wei-Ling, H. Jin-Hung, and C. Chia-Ren, "Wind-induced vibration of high-rise building with tuned mass damper including soil-structure interaction," Journal of Wind Engineering and Industrial Aerodynamics, vol. 96, no. 67, pp. 1092-1102, 2008.
[32] S. Elias and V. Matsagar, "Distributed multiple tuned mass dampers for wind vibration response control of high-rise building," Journal of Engineering, vol. 2014, Article ID 198719, 11 pages, 2014

[33] S. Elias, V. Matsagar, and T. K. Datta, "Effectiveness of distributed tuned mass dampers for multi-mode control of chimney under earthquakes," Engineering Structures, vol. 124, pp. 1-16, 2016.

[34] S. Elias and V. Matsagar, "Effectiveness of tuned mass dampers in seismic response control of isolated bridges including soil-structure interaction," Latin American Journal of Solids and Structures, vol. 14, no. 13, pp. 2324-2341, 2017.

[35] D. De Domenico and G. Ricciardi, "Earthquake-resilient design of base isolated buildings with TMD at basement: application to a case study," Soil Dynamics and Earthquake Engineering, vol. 113, pp. 503-521, 2018.

[36] T. Balendra, C. M. Wang, and G. Rakesh, "Vibration control of various types of buildings using TLCD," Journal of Wind Engineering and Industrial Aerodynamics, vol. 83, no. 1-3, pp. 197-208, 1999.

[37] I. F. Huergo and H. Hernández, "Coupled shear-flexural model for dynamic analysis of fixed-base tall buildings with tuned mass dampers," The Structural Design of Tall and Special Buildings, vol. 28, no. 17, Article ID e1671, 2019.

[38] H. Bachmann, W. J. Ammann, F. Deischl et al., Vibration Problems in Structures: Practical Guidelines, Birkhäuser, Basel, Switzerland, 1995.

[39] C. Christopoulos and A. Filiatrault, Principles of Passive Supplemental Damping and Seismic Isolation, IUSS Press, Pavia, Italy, 2006.

[40] L. M. Sun, Y. Fujino, B. M. Pacheco, and P. Chaiseri, "Modelling of tuned liquid damper (TLD)," Journal of Wind Engineering and Industrial Aerodynamics, vol. 43, no. 1-3, pp. 1883-1894, 1992.

[41] M. A. Steyer, Multifunctionality of Distributed Sloshing Dampers in Buildings, Master thesis, Massachusetts Institute of Technology, Massachusetts, MA, USA, 2002.

[42] V. J. Modi and S. R. Munshi, "An efficient liquid sloshing damper for vibration control," Journal of Fluids and Structures, vol. 12, no. 8, pp. 1055-1071, 1998.

[43] L. M. Sun, Y. Fujino, P. Chaiseri, and B. M. Pacheco, "The properties of tuned liquid dampers using a TMD analogy," Earthquake Engineering \& Structural Dynamics, vol. 24, no. 7, pp. 967-976, 1995.

[44] L. M. Sun and Y. Fujino, "A semi-analytical model for tuned liquid damper (TLD) with wave breaking," Journal of Fluids and Structures, vol. 8, no. 5, pp. 471-488, 1994.

[45] T. K. Caughey, "Equivalent linearization techniques," The Journal of the Acoustical Society of America, vol. 35, no. 11, pp. 1706-1711, 1963.

[46] J. J. Connor, Introduction to Structural Motion Control, Pearson Education, London, UK, 2003.

[47] E. Miranda and C. J. Reyes, "Approximate lateral drift demands in multistory buildings with nonuniform stiffness," Journal of Structural Engineering, vol. 128, no. 7, pp. 840-849, 2002.

[48] N. M. Newmark and W. J. Hall, Earthquake Spectra and Design, Earthquake Engineering Research Institute, Berkeley, California, 1982.

[49] B. Ellis, "An assesssment of the accuracy of predicting the fundamental natural frequencies of buildings and the implications concerning the dynamic analysis of structures," Proceedings of the Institution of Civil Engineers, vol. 69, no. 3, pp. 763-776, 1980. 
[50] B. Stafford and A. Coull, Tall Building Structures: Analysis and Design, Wiley, Hoboken, NJ, USA, 1991.

[51] R. K. Goel and A. K. Chopra, "Period formulas for momentresisting frame buildings," Journal of Structural Engineering, vol. 123, no. 11, pp. 1454-1461, 1997.

[52] R. K. Goel and A. K. Chopra, "Period formulas for concrete shear wall buildings," Journal of Structural Engineering, vol. 124, no. 4, pp. 426-433, 1998.

[53] A. K. Chopra, Dynamics of Structures: Theory and Applications to Earthquake Engineering, Pearson, New Jersey, NJ, USA, 2017.

[54] G. C. Hart and K. Wong, Structural Dynamics for Structural Engineers, Wiley, Hoboken, NJ, USA, 1999.

[55] I. F. Huergo, H. Hernández, and C. M. Patlán, "A continuousdiscrete approach for pre-design of flexible-base tall buildings with fluid viscous dampers," Soil Dynamics and Earthquake Engineering, vol. 131, Article ID 106042, 2020.

[56] R. Soto and S. E. Ruiz, "Influence of ground motion intensity on the effectiveness of tuned mass dampers," Earthquake Engineering and Structural Dynamics, vol. 28, no. 11, pp. 1255-1271, 1999.

[57] S. E. Ruiz and L. Esteva, "About the effectiveness of tuned mass dampers on nonlinear systems subjected to earthquakes," Transactions on the Built Environment, vol. 23, pp. 311-320, 1996.

[58] I. F. Huergo and H. Hernández, "Coupled-two-beam discrete model for dynamic analysis of tall buildings with tuned mass dampers including soil-structure interaction," The Structural Design of Tall and Special Buildings, vol. 29, no. 1, Article ID e1683, 2020.

[59] CFE, Manual de Diseño de Obras Civiles: Diseño por Viento, Instituto de Investigaciones Eléctricas, Cuernavaca, México, 2008.

[60] G. Solari, "Gust buffeting. I: peak wind velocity and equivalent pressure," Journal of Structural Engineering, vol. 119, no. 2, pp. 365-382, 1993.

[61] M. Shinozuka and C.-M. Jan, "Digital simulation of random processes and its applications," Journal of Sound and Vibration, vol. 25, no. 1, pp. 111-128, 1972.

[62] G. Tamura and A. Kareem, Advanced Structural Wind Engineering, Springer, Berlin, Germany, 2013.

[63] K. H. M. Bjørnland, "Wind-induced dynamic response of high rise buildings," Master thesis, Norwegian University of Science and Technology, Trondheim, Norway, 2013.

[64] Y. Quan, M. Gu, and Y. Tamura, "Experimental evaluation of aerodynamic damping of square super high-rise buildings," Wind and Structures, vol. 8, no. 5, pp. 309-324, 2005. 